\title{
Uncertainties in the Estimation of In Situ Stresses: \\ Effects of Heterogeneity and Thermal Perturbation
}

\author{
Hossein Agheshlui ${ }^{\mathrm{a}}$, Stephan Matthai ${ }^{\mathrm{b}}$
}

Peter Cook Centre for CCS, The University of Melbourne, Parkville, Vic 3010, Australia.

a. Corresponding author. Research Fellow. Email: hossein.agheshlui@unimelb.edu.au. Mobile: +61433732225. ORCID ID: 0000-0002-8016-099X.

b. Chair of Reservoir Engineering. Email: stephan.matthai@unimelb.edu.au

\begin{abstract}
In situ stress directions and magnitudes in subsurface are commonly estimated using two different methods: 1) borehole break-out - drilling-induced fracture interpretation complemented by extended leak-off tests; 2) stress estimation from acoustic measurements using advanced wireline tools. Both methods use stress perturbations around boreholes to estimate far field stresses employing Kirsch's equations, which are only valid for boreholes aligned with one of the principal stresses, linear elastic deformation and homogeneous isotropic materials. Furthermore, the original stress state may have been altered by drilling-mud-circulation induced temperature changes. Using heuristic models including heterogeneity, this study investigates potential errors in the estimation of far-field stress due to (a) the generalisation of Kirsch's equations to heterogeneous media and (b) plausible temperature perturbations. First, errors due to uncertainties in measuring wave slowness are analysed for an idealised homogeneous material. Second, errors due to application of Kirsch's equations are investigated considering potential effects of frictional interfaces between layers, pore pressure in the rock matrix and thermal perturbations induced by drilling for example cases. To analyse stress in these complex scenarios Finite Element Analysis (FEA) was used, revealing strong effects of lithological and thermal variations. Stress magnitude was amplified by stiff layers and was attenuated by soft ones. At layer interfaces, substantial changes in stress orientation occurred. Kirsch's equations for the considered cases resulted in errors in far field stresses as large as $44 \%$ in the magnitude and 90 degrees in orientations. An uncertainty propagation analysis indicated a high accuracy of acoustic
\end{abstract}


estimates for homogenous materials. However, a dramatic impact of small-scale heterogeneity may not be resolved by the logging process.

Keywords: stress perturbations around boreholes, Kirsch equations, heterogeneity, thermal stress, acoustic logging, error propagation analysis.

\section{List of Symbols}

$d_{b}$ : borehole diameter $(\mathrm{m})$

$E$ : Young's modulus (GPa)

$f:$ vector of body forces $(\mathrm{N})$

$G$ : Shear modulus $(\mathrm{GPa})$

$K$ : thermal conductivity $(\mathrm{W} /(\mathrm{mK}))$

$p_{p}:$ pore pressure $(\mathrm{MPa})$

$p_{w}:$ wellbore pressure $(\mathrm{MPa})$

$q:$ heat flux $\left(\mathrm{W} / \mathrm{m}^{2}\right)$

S11 : radial stress in a cylindrical coordinate system with its origin set to the wellbore centre.

S22 : hoop stress in a cylindrical coordinate system with its origin set to the wellbore centre.

NT11 : temperature in bedrock.

$T:$ temperature $(\mathrm{K})$

$V_{c}:$ compressive wave velocity $(\mathrm{m} / \mathrm{s})$

$V_{s}:$ shear wave velocity $(\mathrm{m} / \mathrm{s})$

$V_{s l}$ : fast shear wave $(\mathrm{m} / \mathrm{s})$

$V_{s 2}:$ slow shear wave $(\mathrm{m} / \mathrm{s})$

$V_{\text {Stoneley }}:$ Stoneley wave velocity $(\mathrm{m} / \mathrm{s})$

$u, v, w$ : displacements in $\mathrm{x}, \mathrm{y}$, and $\mathrm{z}$ directions $(\mathrm{m})$ 
$\alpha:$ Biot coefficient

$\beta:$ thermal expansivity $(1 / \mathrm{K})$

$\sigma_{H}$ : maximum principal horizontal total far-field stress (MPa)

$\sigma_{h}$ : minimum principal horizontal total far-field stress (MPa)

$\sigma_{v}:$ vertical total stress $(\mathrm{MPa})$

$\sigma_{\theta \min }:$ minimum hoop stress around wellbore (MPa)

$\sigma_{\theta \max }:$ maximum hoop stress around wellbore (MPa)

$\sigma^{\prime}$ : effective stress $(\mathrm{MPa})$

$\varepsilon:$ strain

$\theta:$ angle measured from the major horizontal stress (degrees)

$\mu:$ coefficient of internal friction

$v:$ Poisson's ratio

$\rho:$ rock density $\left(\mathrm{kg} / \mathrm{m}^{3}\right)$

\section{INTRODUCTION}

A knowledge of the in situ stress, both orientation and magnitude, is of critical importance in petroleum engineering, especially for the design of stable well trajectories, hydraulic fracturing, and recovery schemes for fractured reservoirs. Traditionally, stress orientation is inferred from borehole breakouts and drilling-induced fractures interpreted from image logs (Peška and Zoback 1995; Zoback et al. 1986). Today, however, optimal drilling techniques tend to minimize mechanical wellbore failure. Acoustic methods, as an alternative method, utilise stress-induced polarisation of waves as well as changes in the wave speed to infer stress directions and calculate magnitudes with the help of correlations derived from Rock Mechanical Testing (RMT), e.g., (Boness and Zoback 2004; Sayers 2005). These methods are attractive because they can be applied over the entire length of the well including intact sections of the borehole (e.g. Ellis \& Singer (2007)), and it has been argued 
that they alleviate the need to conduct extended leak-off tests. However, this is still subject to a lively debate (e.g., Chang et al. (2006) Gaines et al. (2012)) and of significant commercial interest (e.g., Goodman and Connolly (2007)). For an isotropic elastic rock with well-established elastic moduli, laboratory experiments show that acoustic logging results are fairly accurate (e.g. (Huang et al. 2001)). Real rocks, however, are characterised by significant spatial variations in their mechanical properties (Peng and Zhang 2007). Also, stress interpretation of acoustic logging can be dependent on stress magnitude (e.g. Brandas et al. (2012)). Additionally, there is a difference between static (established by rock mechanical testing, RMT) and dynamic (elevated-frequency, acoustic loggingderived) elastic moduli, which has to be corrected via RMT-derived correlations (e.g. Ellis \& Singer (2007)).

Acoustic logging tools measure the wave slowness over a borehole interval that varies in length between 1 to 3 meters and they accomplish this with a finite accuracy. Dependent on the local geology, this transmitter-receiver distance implies that the wave travels through multiple rock types. Each one of these may have different mechanical properties / poroelastic behaviour, and a unique stress state. Investigation of the latter is the subject of this paper because such small-scale stress variations can be expected to have an influence on the accuracy of stress magnitude determinations and even the detection limit of stress anisotropy that can be achieved by acoustic logging in practice (cf., (Chang et al. 2006)). This detection limit is of particular importance because many hydrocarbon reservoirs reside in a normal-fault regime where $\sigma_{H}-\sigma_{h}$ differences are small $(<3-10 \mathrm{MPa} @<4-\mathrm{km}$ depth, e.g. Zoback (2007)). Notwithstanding, these differences are sufficient to control the orientation of hydraulic fractures. To detect stress directions successfully, the hoop stress must be large enough to create detectable azimuthal variations in the S-wave slowness, see Al-Tahini and Abousleiman (2008); the borehole must be aligned with a principal stress axis and its wall must be free of damage induced by the drilling process. The method will not yield any reliable measurements in the presence of preinherited anisotropy of the rock, although it can detect it (stylolites (Padmanabhan et al. 2015), fractures etc.). Hence there should be no laminations, porosity variations nor lithological banding at a scale below the resolution of supporting logging tools (porosity etc.). Furthermore, the pore fluid 
compressibility and pressures must be known. Given all these issues, the accuracy of acoustic logging derived stresses in practice is unclear. To circumvent some of these limitations, common practice is that acoustic logging analysis for stress is normally restricted to clean sands.

Another concern in the estimation of far-field stress states is the application of the classical Kirsch equations (1898) to the measured stress perturbations around wellbores. This is applicable only to the special case of a vertical well in a homogenous isotropic linear-elastic rock subjected to an Andersonian stress regime (Anderson 1951), which are rarely met in reality. Experimental results show that stresses around wellbores may be over or under estimated when calculated relying on the Kirsch model (Al-Tahini and Abousleiman 2008). Although Kirsch equations were generalized for arbitrarily oriented wells (Peska and Zobak 1995), due to the simplicity of the classical Kirsch equations, they are still used. Also, break-outs and drilling-induced fractures mark strains beyond the linear elastic regime. Furthermore, small-scale layering, laminations, and natural anisotropy of the country rock influence the direction and magnitude of stresses around wellbores (Sirat et al. 2014). Hence, a more general method than Kirsch's is required to establish a firm basis for the quantification of in situ stress.

In this study, error propagation through the stress calculations using acoustic readings is investigated taking into account the known accuracy of wave slowness measurements. Also, the minimum difference between the maximum and minimum horizontal stress required for a correct estimation of stress orientation is discussed.

Then, stress perturbations around boreholes are investigated by means of finite element analysis (FEA). Such methods have recently become more popular in reservoir engineering and geomechanics (e.g. (Grandi et al. 2002; Hoeink et al. 2012; Jha and Juanes 2007)) since they can provide a detailed understanding of the subsurface mechanical behaviour. The FEA conducted here starts with a simple homogenous, isotropic, linear-elastic plain-strain example that serves to verify the chosen FEA model with the Kirsch equations. Then, eight more realistic 3D models are described and analysed. Potential effects of lithologic heterogeneity, frictional interfaces between layers, pore pressure in the rock matrix and thermal perturbations induced by drilling on stress perturbations around wellbores are 
investigated and discussed for the considered cases. Deviations of FEA results from Kirsch predictions are quantified, visualised and interpreted in terms of their implications for in situ stress prediction.

\section{METHODOLOGY}

In reservoir engineering practice, tectonic stress regimes are idealised by assuming that one of the principal subsurface stresses is aligned with the vertical direction and the other two are within the horizontal plane. The stress normal to the earth's surface is denoted by $\sigma_{v}$, while $\sigma_{H}$ and $\sigma_{h}$ denote the maximum and minimum horizontal stresses, respectively. $\sigma_{v}$ corresponds to the overburden stress and it can be estimated with the help of density and porosity logs. Then $\sigma_{H}$ and $\sigma_{h}$ can be inferred from the magnitude and extent of stress perturbations around the borehole. To circumvent the aforementioned issues, where possible, $\sigma_{h}$ is estimated using extended leak-off tests or other methods such as minifracs, etc. Stress directions are inferred from drilling-induced fractures and borehole break-outs $\left(\sigma_{H}\right)$. In their absence, the alternative acoustic logging methods may be used. This situation is becoming increasingly common because of the recent advances in drilling technology producing failure free borehole walls.

In the estimation of far field stresses based on stresses around a wellbore, two sources of error are considered here: (a) errors in estimation of near well stresses, assuming that acoustic logging is used; (b) errors in application of Kirsch's equations to the country rock around the wellbore. In the following, the methodology for estimating the magnitude of these errors is explained.

\subsection{Estimating in situ stress using acoustic logging}

Increasingly stresses around wellbores are estimated from a combination of measurements of compressive, shear and Stoneley wave velocities, denoted respectively by $\mathrm{V}_{\mathrm{c}}, \mathrm{V}_{\mathrm{s}}$ and $\mathrm{V}_{\text {Stoneley. }}$ It has been demonstrated that differences in apparent shear moduli are related to differences in stress magnitude in a homogeneously stressed rock (Sinha 2002). Different methods have been developed to infer in situ stresses from wave slowness such as Sinha et al. (2008), Al-Tahini \& Abousleiman (2008) and Sayers et al. (2009). These methods generally invert differences in dipole dispersions at 
two different well levels in a uniform lithologic interval to the horizontal stress gradient, based on the rock type dispersion curves. The differential stress in a formation will cause shear waves to polarise into two directions: along the maximum horizontal stress direction and along the minimum horizontal stress direction corresponding to the "slow" axis and the "fast" axis in the formation. Wave velocities can also be used to estimate rock mechanical properties such as three orthogonal shear moduli associated with the orthogonal coordinate reference frame.

The method for estimating horizontal stresses investigated in this study is based on shear wave slowness. Measurements of velocities of compressive waves, shear waves and Stoneley waves are required for inferring in situ stress from wave velocities based on validated and calibrated dispersion curves for a given formation using the following procedure. It requires readings from a sonic scanning tools that is equipped with both monopole and cross-dipole transmitters and can make measurements in radial, azimuthal and axial directions (Schlumberger, 2005).

1. Estimation of rock mechanical properties. These can either be estimated by Rock Mechanical Testing (RMT) of the formation of interest or from generic RMT-based correlations with wave velocities measured by wellbore logging tools. Since the interest here is to investigate potential errors using acoustic stress measurements along the entire section of interest of the borehole, it is assumed that the mechanical properties are obtained from wave velocities. Although errors and uncertainties also exist in the RTM measurements, these are not discussed in this paper. The only source of error considered here is the uncertainty in the measurements made by the sonic logging tools. For sonic stress logging, Young's modulus, $E$ and Poisson's ratio, $v$ are calculated using equations (1) and (2).

$$
\begin{gathered}
E=\frac{\rho V_{s}^{2}\left(3 V_{c}^{2}-4 V_{s}^{2}\right)}{V_{c}^{2}-V_{s}^{2}} \\
\vartheta=\frac{V_{c}^{2}-2 V_{s}^{2}}{2\left(V_{c}^{2}-V_{s}^{2}\right)}
\end{gathered}
$$

where, $\rho$ is the rock density, $V_{s}$ is the monopole shear velocity and $V_{c}$ is the compression wave velocity. 
2. Estimation of the principal shear moduli of rock using fast and slow shear wave as well as Stoneley wave velocity from eq. (3). In the ideal homogeneous isotropic case, the three shear moduli will have the same value, corresponding to the shear modulus $(G)$. However, in reality three independent shear moduli are needed to describe the difference in the behaviour of the rock in the three orthogonal directions. Such a material is called orthotropic and has three orthogonal plains of microstructural symmetry.

$$
\begin{gathered}
C_{44}=V_{s 2}^{2} * \rho_{d r y} \\
C_{55}=V_{s 1}^{2} * \rho_{d r y} \\
C_{66}=V_{\text {stoneley }}^{2} * \rho_{d r y}
\end{gathered}
$$

3. Estimation of $\sigma_{V}$ by integrating the bulk density of the overlaying layers:

$$
\sigma_{V}=g \int_{0}^{z}\left(\rho_{d r y}(z)+\rho_{w}(z)\right) d z
$$

where $\rho_{w}$ is the pore fluid density. In case of offshore wells, the weight of the water column on top of the rock layers needs to be accounted for as well. It is worth mentioning that density logs are also prone to errors, particularly due to the rugose hole conditions.

4. Estimation of $\sigma_{h}$ using the following equations (2009).

$$
\sigma_{h}=\frac{\vartheta}{1-\vartheta}\left(\sigma_{V}-\alpha p_{p}\right)+\alpha p_{p}
$$

with a lower bound on $\sigma_{h}$ given by the stability condition for a critically oriented fault in a frictional equilibrium:

$$
\frac{\left(\sigma_{V}-\alpha p_{p}\right)}{\left(\sigma_{h}-\alpha p_{p}\right)}=\left[(\mu+1)^{1 / 2}+\mu\right]^{2}
$$

where $\mu$ is the coefficient of internal friction, assumed to be 0.6 for the shallow continental crust (Zoback and Healy 1984); $\alpha$ is the Biot coefficient.

5. Estimation of $\sigma_{H}$ using the following equation (Sayers et al. 2009): 


$$
\sigma_{H}=\sigma_{h}+\frac{C_{55}-C_{44}}{C_{55}-C_{66}}\left(\sigma_{V}-\sigma_{h}\right)
$$

With the five steps above, all principal stresses can be calculated provided that one has measured the compressive, shear and Stoneley wave velocities accurately. Equation (5) is derived from the constitutive equation of poroelasticity assuming an isotropic linear homogenous material. Also, it was assumed that horizontal stresses are equal, horizontal strains are zero, the tectonic strains are insignificant, vertical stresses are applied instantaneously and that the poisson effect is the source of horizontal stress. These create limitations and errors in the application of this equation in reality. Moreover, there are uncertainties involved in the measurement of the wave velocities which influence the estimated stresses. These will require an in depth separate study. Here, only the influence of uncertainties in the wave velocities is discussed in the following.

\subsection{Uncertainties and error propagation in acoustic readings}

Sonic logging tools measure wave velocities with a certain accuracy. Current sonic logging tools produced by Schlumberger, for instance, are reported to measure wave slowness with an accuracy of $150 \mathrm{~m} / \mathrm{s}$ (Schlumberger 2005). The waves created by these tools travel between $1 \mathrm{~m}$ to $3 \mathrm{~m}$ through the formation before being detected. The wave speed is averaged over this length although it may vary considerably due to heterogeneity and related variations in the stress state. However, the only uncertainty we consider in our sensitivity analysis is that ensuing from the limited accuracy of the measurements. These uncertainties propagate through the calculations for estimating stresses and create larger errors in the final estimates. A Monte Carlo simulation with 100,000 model realisations was conducted defining $\mathrm{V}_{\mathrm{c}}, \mathrm{V}_{\mathrm{s} 1}, \mathrm{~V}_{\mathrm{s} 2}$ and $\mathrm{V}_{\text {Stoneley }}$ as probabilistic variables with the potential error of $\pm 150 \mathrm{~m} / \mathrm{s}$. A normal distribution function was assumed to characterise wave velocity with a $99.8 \%$ probability of occurrence in a range of $\mathrm{V} \pm 150 \mathrm{~m} / \mathrm{s}$, where $\mathrm{V}$ refers to any of the measured wave velocities. The same measurement inaccuracy was assumed in every model realisations for $V_{S 1}, V_{S 2}$ and $V_{\text {Stoneley }}$ since they all are shear waves $\left(V_{\text {stoneley }}\right.$ behaves as a tubular shear wave after it reaches the rock). However, since compressional waves are fundamentally different from shear waves, a different value of inaccuracy was assumed for $\mathrm{V}_{\mathrm{c}}$, in every model realisations. In other words, $V_{S 1}, V_{S 2}$ and 
$V_{\text {stoneley }}$ were assumed to be dependant random variables while $V_{c}$ was independent from the other wave velocities.

Two different common scenarios were considered in this study: (1) $\sigma_{H}$ and $\sigma_{h}$ were both calculated from measured wave velocities; (2) $\sigma_{h}$ was measured using an extended leak-off test, then $\sigma_{H}$ was calculated from wave velocities measured by sonic logging tools. The values used for the MonteCarlo analysis along with their sources are given in Table 1.

\subsection{Kirsch's equations}

The Kirsch equations were originally developed to estimate the hoop and radial stresses around a hole in a homogenous infinite plate under unidirectional tension and assuming a plane-strain case (Kirsch 1898). For a more general case of bi-directional loading of a vertical wellbore with an internal pressure of $p_{w}$, the Kirsch equations have been modified as (Fjær et al. 2008):

$$
\begin{gathered}
\sigma_{\mathrm{r}}=\frac{\sigma_{\mathrm{H}}+\sigma_{\mathrm{h}}}{2}\left(1-\frac{R_{w}^{2}}{r^{2}}\right)+\frac{\sigma_{\mathrm{H}}-\sigma_{\mathrm{h}}}{2}\left(1+3 \frac{R_{w}^{4}}{r^{4}}-4 \frac{R_{w}^{2}}{r^{2}}\right) \cos (2 \theta)+p_{w} \frac{R_{w}^{2}}{r^{2}} \\
\sigma_{\theta}=\frac{\sigma_{\mathrm{H}}+\sigma_{\mathrm{h}}}{2}\left(1+\frac{R_{w}^{2}}{r^{2}}\right)-\frac{\sigma_{\mathrm{H}}-\sigma_{\mathrm{h}}}{2}\left(1+3 \frac{R_{w}^{4}}{r^{4}}\right) \cos (2 \theta)-p_{w} \frac{R_{w}^{2}}{r^{2}} \\
\tau_{r \theta}=-\frac{\sigma_{H}-\sigma_{h}}{2}\left(1-3 \frac{R_{w}^{4}}{r^{4}}+\frac{2 R_{w}^{2}}{r^{2}}\right) \sin (2 \theta)
\end{gathered}
$$

where $r$ is the radial distance from the borehole axis of the point for which radial and circumferential stresses are calculated. $R_{w}$ is the wellbore radius, and $\theta$ is the angle measured from the major horizontal stress. Here, $\sigma$ refers to total stresses without incorporating and thermal stresses. These extended equations do not apply to deviated wells in non-horizontal layers, heterogeneous materials or obliquely oriented stress fields.

Although the original form of Kirsch's equations is arranged to estimate the stress concentrations around a borehole due to the known far field stresses, the main application of these equations in subsurface geomechanics is to estimate far field stresses having the measurements of near well stresses. Assuming that the minimum and maximum hoop stresses at the wellbore surface (i.e. $r=R_{w}$ ) are measured, notated here by $\sigma_{\theta \min }$ and $\sigma_{\theta \max }$ and are associated respectively with orientations of $\theta=$ 
$0^{\circ}$ and $\theta=90^{\circ}$, equation (8) can be rearranged to be solved for far field stresses, as given by equation (9).

$$
\begin{gathered}
\sigma_{h}=\frac{3}{8} \sigma_{\theta \min }+\frac{1}{8} \sigma_{\theta \max }+\frac{p_{w}}{2} \\
\sigma_{H}=\frac{1}{8} \sigma_{\theta \min }+\frac{3}{8} \sigma_{\theta \max }+\frac{p_{w}}{2}
\end{gathered}
$$

\subsection{Errors due to application of Kirsch's Equations}

Equation (9) can be employed for calculation of errors in the estimation of far field stresses due to the use of Kirsch's equations. depicts the flowchart for this process. First, a Mechanical Earth Model (MEM) with certain far field stresses applied to it is built. Then, FEA is used for the estimation of stresses around the wellbore considering material heterogeneity and thermal effects. For comparison purposes, this step can also be done using Kirsch's equations given by equation (8) which may cause errors which are discussed later in the paper. Having the wellbore stresses calculated by FEA, far field stresses can be estimated using rearranged Kirsch's equations, i.e. equation (9). A comparison between the input far field stresses and those calculated by Kirsch's equations will illustrate the errors of this commonly used process.

In practice, stresses around wellbore, part B in, are measured using sonic logging tools or by conducting extended leak-off tests.

\subsection{Finite Element Analysis (FEA)}

A more versatile method for estimating the stresses around boreholes than the Kirsch equations is forward modelling using FEA. Such models can incorporate material heterogeneity, material and geometrical nonlinearity, layering, frictional interfaces, and complex geometries. A displacement based elastic quadratic finite element method is used here to solve the linear elasticity equations over the domain of interest. Static equilibrium is described by Cauchy's equation in vectorial form (Malvern 1969):

$$
\nabla \underline{\sigma}+\boldsymbol{f}=0
$$


Where $\underline{\boldsymbol{\sigma}}$ is the $3 \times 3$ second order stress tensor and $\boldsymbol{f}$ is the vector of body forces that act on the rock volume. In general, $\sigma_{i j}=\sigma_{j i}$; hence the stress tensor has only six unknown components while three equations are given. The three other equations required, can be derived from Hook's law relating displacements to strains and in turn to stresses:

$$
\underline{\sigma}=\underline{C} \underline{\varepsilon}
$$

where $\underline{\boldsymbol{\varepsilon}}$ is the strain tensor and, in the most general case, $\underline{\boldsymbol{C}}$ is a fourth-order six-by-six tensor. However, an isotropic material can be characterised using just two elastic constants, the Young's modulus $(E)$ and Poisson's ratio $(v)$. For a unidirectional loading in the $z$ direction:

$$
\begin{aligned}
& E=\sigma_{z z} / \varepsilon_{z z} \\
& \vartheta=\varepsilon_{y y} / \varepsilon_{z z}
\end{aligned}
$$

The strain tensor is defined by:

$$
\underline{\boldsymbol{\varepsilon}}=\left[\begin{array}{ccc}
\varepsilon_{x} & \gamma_{x y} & \gamma_{z x} \\
\gamma_{x y} & \varepsilon_{y} & \gamma_{y z} \\
\gamma_{z x} & \gamma_{y z} & \varepsilon_{z}
\end{array}\right]
$$

Strains are derived from displacements by the following definitions, where $(u, v, w)$ is the displacement vector:

$$
\begin{array}{ll}
\varepsilon_{x}=\frac{\partial u}{\partial x} ; & \varepsilon_{x y}=\frac{\gamma_{x y}}{2}=\frac{1}{2}\left(\frac{\partial u}{\partial y}+\frac{\partial v}{\partial x}\right) \\
\varepsilon_{y}=\frac{\partial v}{\partial y} ; & \varepsilon_{y z}=\frac{\gamma_{y z}}{2}=\frac{1}{2}\left(\frac{\partial v}{\partial z}+\frac{\partial w}{\partial y}\right) \\
\varepsilon_{z}=\frac{\partial w}{\partial z} ; & \varepsilon_{z x}=\frac{\gamma_{z x}}{2}=\frac{1}{2}\left(\frac{\partial w}{\partial x}+\frac{\partial u}{\partial z}\right)
\end{array}
$$

Using $E$ and $v$, Hook's law reduces to: 


$$
\begin{array}{ll}
\sigma_{x}=\frac{E}{1+\vartheta}\left(\varepsilon_{x}+\frac{\vartheta}{1-2 \vartheta}\left(\varepsilon_{x}+\varepsilon_{y}+\varepsilon_{z}\right)\right) ; \quad \tau_{x y}=G \gamma_{x y} \\
\sigma_{y}=\frac{E}{1+\vartheta}\left(\varepsilon_{y}+\frac{\vartheta}{1-2 \vartheta}\left(\varepsilon_{x}+\varepsilon_{y}+\varepsilon_{z}\right)\right) ; \quad \tau_{y z}=G y z \\
\sigma_{z}=\frac{E}{1+\vartheta}\left(\varepsilon_{z}+\frac{\vartheta}{1-2 \vartheta}\left(\varepsilon_{x}+\varepsilon_{y}+\varepsilon_{z}\right)\right) ; \quad \tau_{z x}=G \gamma_{z x}
\end{array}
$$

In a cylindrical coordinate system equation (16) changes to:

$$
\begin{aligned}
& \sigma_{r}=\frac{E}{(\vartheta+1)(2 \vartheta-1)}\left((\vartheta-1) \varepsilon_{r}+\vartheta\left(\varepsilon_{\theta}+\varepsilon_{z}\right)\right) ; \quad \tau_{r \theta}=G \gamma_{r \theta} \\
& \sigma_{\theta}=\frac{E}{(\vartheta+1)(2 \vartheta-1)}\left((\vartheta-1) \varepsilon_{\theta}-\vartheta\left(\varepsilon_{r}+\varepsilon_{z}\right)\right) ; \quad \tau_{r z}=G_{r z} \\
& \sigma_{z}=\frac{E}{(\vartheta+1)(2 \vartheta-1)}\left((\vartheta-1) \varepsilon_{Z}-\vartheta\left(\varepsilon_{r}+\varepsilon_{z}\right)\right) ; \quad \tau_{\theta z}=G \gamma_{\theta z}
\end{aligned}
$$

Where the shear modulus $G$ is defined as:

$$
G=\frac{E}{2(1+\vartheta)}
$$

Substituting equation (16) into (11) reduces the number of unknowns to three, which, if inserted into equation (10), can be solved. The final equation for stress is:

$$
\nabla \underline{C} . \nabla \underline{\varepsilon}+f=0
$$

\subsection{Stress-Strain Analysis Including Thermal Effects}

Coupled thermal-stress analysis has been included in this research to investigate the effect of drillingmud-circulation induced thermal stress perturbations around boreholes. Only steady state cases are considered here, where the temperature at any point in the domain is computed from Fourier's law entering the heat equation:

$$
K \nabla^{2} T=q
$$

where $T(x, y, z)$ is the temperature (K) field, $K$ is the thermal conductivity $(\mathrm{W} /(\mathrm{mK}))$ and $q$ is the heat flux across the boundaries $\left(\mathrm{W} / \mathrm{m}^{2}\right)$. 
Most materials expand if the temperature is increased and contract when cooled. For most rocks, it is sufficiently accurate to assume that this expansion is linearly related to the temperature change. This proportionality is captured by the parameter thermal expansivity. If the expansion is not restrained, all dimensions will expand equally with no change in the shape, i.e. no shear strain (Barber 2010). Thermal strains are additive to elastic strains. Hence, eq. (16) is readily extended to include thermal strains:

$$
\begin{aligned}
& \sigma_{x}=\frac{E}{1+\vartheta}\left(\epsilon_{x}+\frac{\vartheta}{1-2 \vartheta}\left(\epsilon_{x}+\epsilon_{y}+\epsilon_{z}\right)\right)-\frac{E \beta \Delta T}{1-2 \vartheta} ; \quad \tau_{x y}=G \gamma_{x y} \\
& \sigma_{y}=\frac{E}{1+\vartheta}\left(\epsilon_{y}+\frac{\vartheta}{1-2 \vartheta}\left(\epsilon_{x}+\epsilon_{y}+\epsilon_{z}\right)\right)-\frac{E \beta \Delta T}{1-2 \vartheta} ; \quad \tau_{y z}=G_{y z} \\
& \sigma_{z}=\frac{E}{1+\vartheta}\left(\epsilon_{z}+\frac{\vartheta}{1-2 \vartheta}\left(\epsilon_{x}+\epsilon_{y}+\epsilon_{z}\right)\right)-\frac{E \beta \Delta T}{1-2 \vartheta} ; \quad \tau_{z x}=G \gamma_{z x}
\end{aligned}
$$

where $\beta$ is the linear thermal expansion coefficient $\left(\mathrm{K}^{-1}\right)$.

\subsection{Frictional Interfaces}

Frictional interfaces are defined by separating the mesh at the interfaces of different layers. The interaction between the resulting surfaces is constrained to avoid interpenetration while a frictional behaviour is defined in the tangential direction. A basic Coulomb friction model was used with the tangential stress required for sliding given by the following equation (Coulomb 1773):

$$
\tau=f \sigma_{n}^{\prime}
$$

where $\tau$ is the tangential stress, $\sigma_{n}^{\prime}$ is the effective stress normal to the considered surface and $f$ is the friction coefficient. Byerlee (1978) showed that for a very wide range of rock types at high effective normal stresses $(\geq \sim 10 \mathrm{MPa})$, friction on faults is independent of surface roughness, normal stress, rate of slip, etc, and it is generally between 0.6 and 1.0. Here, a value of 0.6 is used conservatively. The effective stress needs to be used here because the pore-fluid that does not sustain shear stress at slow deformation rates counteracts the interface-normal stress. The effective stress, $\sigma^{\prime}$, is simply calculated by subtracting the pore pressure from the total stress at any given point in porous media. 


$$
\sigma^{\prime}=\sigma-p_{p}
$$

where $p_{p}$ is the pore pressure. Note that the pore pressure reduces the tangential stress that can be sustained by an interface. In this study, models including frictional interfaces have been analysed with and without pore pressure to elucidate this behaviour.

\subsection{Model Setup for FEA}

Different FEA models were developed using finite element method to study the nature of stress perturbations around boreholes. First, the implementation of the finite element method used was verified using a linear homogenous $2 \mathrm{D}$ plane-strain model with a size of $2.1 \mathrm{~m} \times 2.1 \mathrm{~m}$ and a $0.3 \mathrm{~m}$ diameter hole in the centre. Boundary stresses of $63.75 \mathrm{MPa}$ and $56.25 \mathrm{MPa}$ were applied along the coordinate axes. These numbers were selected based on the assumption of the borehole being located at $3 \mathrm{~km}$ depth with $\sigma_{V}=75 \mathrm{MPa}, \sigma_{H}=0.75 \times \sigma_{V}$, and $\sigma_{h}=0.85 \times \sigma_{V}$.

Second, inhomogeneous more realistic 3D models were developed and analysed. Four different models were developed. All the developed models were $4 \mathrm{~m}$ high and $2.1 \mathrm{~m}$ wide with a borehole inside with a diameter of $d_{b}=0.3 \mathrm{~m}$ (Figure 2). Three different sets of mechanical properties were applied to the layers of all the models (Table 3). Model A, B, and C had the same layering order (Figure 2 (a)\&(b)), from the top to the bottom, Sandstone, Shale and Limestone, and they incorporated a vertical well, a well with 11 degrees deviation, and a well with 22 degrees deviation, respectively. To provide a minimum distance of $3 \times d_{b}$ from between the well edge and the side walls, the width of these models were selected to be $2.1 \mathrm{~m}, 2.9 \mathrm{~m}$, and $3.8 \mathrm{~m}$, for models A to C respectively. This was necessary to avoid near-boundary effects on the results. Model D was a cross-bedded geological model with complex layering, Figure 2 (c). Confining stresses equivalent to a subsurface depth of $3 \mathrm{~km}$ were factored into the applied boundary stresses of $\sigma_{V}=75 \mathrm{MPa}$ (Y direction), $\sigma_{H}=$ 63.25MPa (X direction), $\sigma_{h}=56.25 \mathrm{MPa}$ ( $\mathrm{Z}$ direction). The fluid pressure in the borehole was set to hydrostatic $\left(p_{w}=30 \mathrm{MPa}\right)$. Zero displacement boundary conditions were applied on the opposite sides of the applied loads in the $\mathrm{X}, \mathrm{Y}$ and $\mathrm{Z}$ directions. 
Using these four models, eight different analysis cases were conducted to study stress perturbations around boreholes. These are listed in Table 2 .

\section{RESULTS: ERRORS IN STRESS ESTIMATION USING ACOUSTIC LOGGING}

In this section, the potential stress estimation errors due to the limited accuracy of wave velocity measurements using sonic logging tools are presented.

\subsection{Error propagation due to measurement accuracy}

Performing Monte-Carlo analysis with 100,000 model realisations, the values of $\sigma_{H}$ (only for case 1) and $\sigma_{h}$ along with their precisions in different confidence levels were calculated as shown in Table 4.

Results from Case 2 shows that if $\sigma_{h}$ is known reliably based on the field data and, as assumed earlier on, $\mathrm{V}_{\mathrm{S} 1}, \mathrm{~V}_{\mathrm{S} 2}$ and $\mathrm{V}_{\text {Stoneley }}$ have the same measurement accuracy, the precision of the $\sigma_{H}$ estimate will be very high, i.e., there will be insignificant errors in the $\sigma_{H}$ calculation. As mentioned earlier, the only source of error considered in this study is the measurement accuracy of acoustic tools. If both, $\sigma_{H}$ and $\sigma_{h}$ are estimated from wave velocities the potential error still remains only a few percent. However, this high precision is limited to the case of a homogeneous isotropic material which is rare in nature.

\subsection{Minimum required difference between horizontal principal stresses}

In estimating stresses using acoustic logging, the difference between the maximum and minimum horizontal stresses is calculated based on the difference between the fast and slow shear wave velocities. As mentioned earlier, sonic tools can measure wave velocities to a certain accuracy, for instance $150 \mathrm{~m} / \mathrm{s}$ (Schlumberger 2005). If it is assumed that the uncertainties in measuring $\mathrm{V}_{\mathrm{s} 1}$ and $\mathrm{V}_{\mathrm{s} 2}$ are independent, a minimum difference of $300 \mathrm{~m} / \mathrm{s}$ would be required between them to make sure that $\mathrm{V}_{\mathrm{s} 1}$ and $\mathrm{V}_{\mathrm{s} 2}$ are recorded in the correct order, as illustrated in Figure 3. Depending on the mechanical properties of rock and stress levels, $300 \mathrm{~m} / \mathrm{s}$ difference in shear wave velocity can translate to different levels of difference between $\sigma_{\theta \max }$ and $\sigma_{\theta \min }$. For the case considered in Section 3.1, assuming $V_{S I}=$ $V_{S 2}+300 \mathrm{~m} / \mathrm{s}$ and using the method explained in Section 2.1, $\sigma_{H}$ and $\sigma_{h}$ were found to be 23.0 MPa and 12.7 MPa. In this case, $300 \mathrm{~m} / \mathrm{s}$ difference between $\mathrm{V}_{\mathrm{s} 1}$ and $\mathrm{V}_{\mathrm{s} 2}$ translate into a difference between $\sigma_{H}$ 
and $\sigma_{h}$ of 10.3 MPa. This means that for the considered case here, any difference between $\sigma_{H}$ and $\sigma_{h}$ that is less than this value may not be resolved.

The result obtained above is not correct if errors in measuring $V_{S 1}$ and $V_{S 2}$ are dependent, i.e. the same amount of error exist in $V_{S 1}$ and $V_{S 2}$ (while both velocities have the same standard deviation). In that case, the difference between shear wave velocities will be preserved. Hence, the orientation of minimum and maximum stresses will be estimated correctly, although different levels of errors will still exist in the estimates of the principal stresses (depending on the magnitude of measurement errors in shear wave velocity). For the considered case study, the maximum error in the estimation of the magnitude of $\sigma_{H}$ was found to be $3.6 \mathrm{MPa}$ which is still significant, especially that very small differences between principal stresses are likely to exist in unconsolidated sand reservoirs due to consolidation and creep effects (e.g., Zoback (2007)) or in over pressured formations.

\section{RESULTS: FINITE ELEMENT ANALYSIS}

Results from the finite-element analysis carried out on Models A-G are presented here. For the 2D isotropic homogeneous plane-strain case, the stress distribution around the borehole is shown in Figure 4. The comparison between hoop stresses from FEM and Kirsch's equations reveals a minor deviation of the FEM of less than $2 \%$ in terms of the maximum and minimum hoop stresses (Figure 5). This good agreement validates the accuracy of the FEM. For more general cases, Kirsch's equations may not produce the correct results, as will be shown further below.

In the following, the results of the layered Models B-G are presented. The displayed stress contours are all presented in a cylindrical coordinate system with an origin located at the centre of the well. The $\mathrm{Y}$ direction is oriented along the well axis. Magnitude and direction of stresses given in all the graphs are obtained by cutting sections in the vertical direction at $0.05-\mathrm{m}$ intervals creating 60 sections, and comparing results at 72 points on the edge of the borehole for each section.

\subsection{Case A. The effect of layering on the stresses around a vertical well}

In Case A, the influence of layering on the stresses around the vertical hole was investigated. The layers were assumed to be bonded to each other and included sandstone, shale and limestone from the 
top to the bottom, see Table 3. Figure 6 presents the hoop stresses in two orthogonal vertical sections in terms of minimum and maximum values. Figure 7 illustrates the change of $\sigma_{\theta \max }$ and $\sigma_{\theta \min }$ along the wellbore. It shows that significant changes of stress occur when moving from one layer to another with an increase of magnitude in the stiffer layer and a decrease in the softer layer. Despite the importance of these changes, they cannot be captured using Kirsch's equations since they are due to material inhomogeneity.

\subsection{Model B: slightly deviated borehole in layered rocks}

In case B, a deviated well with an inclination angle of 11 degrees was considered. Stress distributions in the maximum and minimum directions are shown in Figure 8. Figure 9 presents the variations in the stress magnitude and the directions of $\sigma_{\theta \max }$ and $\sigma_{\theta \min }$.

\subsection{Case C: highly deviated borehole in layered rocks}

Figure 10 shows the stress distribution for a deviated well with 22 degrees inclination and Figure 11 shows the stress magnitude and orientation along the well. The deviation from the predictions made by the Kirsch equations are more pronounced and a 90 degrees change of stress orientation occurs when moving from the stiffer limestone layer to the softer shale layer.

\subsection{Case D: thermal perturbations in a highly deviated borehole}

In Case D, the effect of a borehole-centered thermal perturbation on the stresses around a wellbore is investigated. As stated earlier, it was assumed that the temperature of the formation, located at $3 \mathrm{~km}$ depth, was $100^{\circ} \mathrm{C}$, but the mud circulation reduced the temperature of the borehole wall by $30^{\circ} \mathrm{C}$. This quasi steady state case was analysed applying constant temperature boundary conditions of $70^{\circ} \mathrm{C}$ to the borehole wall and $100^{\circ} \mathrm{C}$ to the exterior surfaces of the model, see. Figure 12 .

Figure 13 shows the ensuing variations in the stresses around the wellbore and Figure 14 compares the maximum hoop stresses for cases with and without thermal perturbation (Cases D and E). Due to the thermal contraction, the hoop stresses are reduced by $2 \mathrm{MPa}$ to $9 \mathrm{MPa}$. It follows that if thermal perturbations are not corrected for, considerable errors will be made in the stress estimation. 


\subsection{Case E: highly deviated borehole in layered rocks with frictional sliding interfaces}

In Models $\mathrm{B}$ and $\mathrm{C}$, a perfect bond was implemented between layers by creating a contiguous mesh with no discontinuities in the entire solution domain. Only the material properties were varied from layer to layer. By contrast, Model E consists of separate meshes for each layer. Their interaction is constrained by frictional interfaces as has been explained in Section 2.7. Stress distribution and magnified deformation of the model due to the applied loads are shown in Figure 15, in which finite sliding of the layers relative to one another can be noticed. Figure 16 depicts the accompanying variation of hoop stress magnitudes, as well as the orientation of the maximum hoop stress around the well.

\subsection{Case F: Pore pressure effects on frictional interfaces in a highly deviated borehole}

The pore pressure reduces the effective stress and consequently the shear stress required for sliding (Zoback 2007). This phenomenon may influence the stresses and deformations around a wellbore and it is of interest to quantify the extent of potential change.

This simulation is conducted on Model C considering two different levels of pore pressure implemented in all of the layers, including (a) hydrostatic pore pressure and (b) an extreme case of a pore pressure as twice as the hydrostatic pore pressure. For case (a), the distribution of effective hoop stress is shown in Figure 17 and the magnitude and orientation of $\sigma_{H}{ }_{H}$ and $\sigma_{h}{ }_{h}$ are presented in Figure 18. Figure 19 compares the total hoop stresses around the wellbore for these cases. Although the general trends were similar, a difference between the results existed. For the considered cases, the maximum difference in $\sigma_{\theta \min }$ was observed at the interfaces of the layers (i.e. the maximum stiffness change) with a magnitude of $7.1 \mathrm{MPa}(15.4 \%)$. Also, the maximum difference in $\sigma_{\theta \max }$ occurred in the middle of the shale layer with a magnitude of $4.9 \mathrm{MPa}(4.7 \%)$. In the shale and limestone layers, the difference between the $\sigma_{\theta \max }$ and $\sigma_{\theta \min }$ was reduced in case (b) where a higher pore pressure was assumed. 


\subsection{Case Model G. Geological model including frictional interfaces}

To investigate stress perturbations around a wellbore due to heterogeneity associated with lithologic layering, a model representing cross bedding including thinning and pinchouts was built (Figure 2(c)). All layer boundaries were modelled as frictional interfaces. Figure 20 depicts the ensuing stress distribution around the wellbore and Figure 21 along the wellbore trajectory. These strong variations are effectively ignored when stresses are estimated using Kirsch's equations or averaged over the length of the tools if sonic logging is used.

\subsection{Case H: cross-bedded geological model with the effects of thermal perturbations}

In this case the effect of temperature reduction during drilling the wellbore is considered. The temperature at the borehole wall was reduced by $30^{\circ} \mathrm{C}$. The temperature in the country rock and the stress distribution in the direction of $\sigma_{H}$ are shown in Figure 22. Figure 23 presents the stress magnitude and orientation around the wellbore. Figure 24 shows a comparison between the maximum hoop stresses of cases Case $\mathrm{H}$ and $\mathrm{G}$ to investigate the thermal effects on stress perturbations around wellbores. A change range of $-0.2 \mathrm{MPa} \sim 7.9 \mathrm{MPa}$ was observed due to thermal effects.

\section{DISCUSSION}

This paper discusses the stress perturbations near wellbores which is of significant importance in applications such as design of stable well trajectories and hydraulic fracturing. Previous studies have investigated the influence of anisotropy. For instance, analytical solutions have been presented for the estimation of stress concentration around inclined boreholes in anisotropic elastic media by Abousleiman (2005) and Gaede et al. (2012). However, these solutions are developed for homogenous material, hence they cannot be applied to regions with non-symmetrical layering and do not estimate the near boundary effects. As demonstrated in this paper, these effects may have major influences on stress states around wellbores.

3D models of the well and the surrounding bedrock were created and the stress perturbations around the wellbore were simulated numerically considering effects such as frictional interfaces between layers, borehole deviation and formation pore pressure. Errors in estimating horizontal principal 
stresses using sonic logging and the subsequent implementation of Kirsch's equations were investigated. For sonic logging tools, only the influence of the accuracy of the wave velocity measurements was investigated for an isotropic case. It was observed that the error in the estimation of $\sigma_{H}$, via $\sigma_{h}$, inferred from an extended leak-off test, is insignificant, assuming that the magnitudes of errors in measuring $\mathrm{V}_{\mathrm{s} 1}, \mathrm{~V}_{\mathrm{s} 2}$ and $\mathrm{V}_{\text {Stoneley }}$ are the same due to their shared shear-wave nature. However, since $\sigma_{h}$ is not normally measured by conducing extended leak-off tests in practice, there will be considerable errors in the estimation of $\sigma_{H}$ and $\sigma_{h}$. For the case considered in this study, approximately $7 \%$ error was observed in measuring in situ stresses with a confidence level of $99.8 \%$. A maximum absolute error of 3.6 MPa (20\% approximately) entered the stress magnitudes in the case studied here.

It must be noted that in the conducted analysis, other sources of error in acoustic logging were not considered. An important example is the averaging effect along the travel length of waves from transmitters to receivers. This may not be a significant issue for relatively homogenous thick layers, and when measurements are made away from the layer boundaries. However, as shown previously in this paper and also observed by numerical simulations and wellbore logs (Boness and Zoback 2004; Hoeink et al. 2012) stresses may change significantly in the magnitude as well as orientation when moving from one layer to another. These may be underestimated or even cancelled out due to averaging done by sonic tools. This effect will especially be important for relatively thin layers. The magnitude of errors due to averaging would depend on the stress jumps at the interfaces of layers and can potentially be significant. These will require a separate study.

Finite element simulation of stress perturbations around the wellbore provided an understanding of the actual changes that may occur in stresses around wellbores due to the factors such as lithological heterogeneity and thermal effects. In Case A, due to the difference in the stiffness of layers, a sudden change occurred in stress magnitudes around the interfaces of layers with an increase in the stiffer layer and a decrease in the softer layer. Also, near the interfaces, the difference between $\sigma_{\theta \max }$ and $\sigma_{\theta \min }$ increased in the stiffer layer and decreased in the softer layer. These changes were more dramatic when the layers were relatively thin (e.g. cases $\mathrm{G}$ and $\mathrm{H}$ ). 
Two cases of B and C were considered with different well deviations to investigate the influence of well deviation on stresses around wellbores. Changes similar to case A were observed in the stress magnitudes. For Case B (11 degrees inclination), a reduction, more than Case A, was observed in the difference between $\sigma_{\theta \max }$ and $\sigma_{\theta \min }$ in the softer shale layer sandwiched by the two stiffer layers. For Case C (22 degrees inclination) the reduction in $\sigma_{\theta \max }$ and $\sigma_{\theta \min }$ was more than cases A and B and it was observed in all layers. Changes of the orientation of stresses were up to 90 degrees for this case, i.e. reversal of the directions of $\sigma_{\theta \max }$ and $\sigma_{\theta \min }$ which causes the same error in the estimation of the orientation of far field stresses.

Case $\mathrm{D}$ was different from Case $\mathrm{C}$ in that a temperature reduction of -30 Celsius degrees was applied to the wellbore surface. This resulted in a reduction of near wellbore hoop stresses of $2.2 \mathrm{MPa}$ $7.8 \mathrm{MPa}\left(0.2 \% \sim 8.1 \%\right.$ of $\left.\sigma_{V}\right)$ which could not be captured using standard Kirsch's equations. Also, such changes in stress magnitudes could cause errors in estimating far filed stresses based on near well wave velocities.

In Case $\mathrm{E}$, the interfaces between layers of Case $\mathrm{C}$ were changed to frictional interfaces with a friction coefficient of 0.6. The stress magnitudes and orientations along the wellbore were similar to Case $\mathrm{C}$ in their general trend, however some changes were observed. The effects would have been significant if sliding was observed.

Case $\mathrm{F}$ investigated the influence of different levels of pore pressure in the stress perturbations around wellbores. In a higher pore pressure level, the difference between $\sigma_{\theta \max }$ and $\sigma_{\theta \min }$ was increased at the interfaces of the layers; however it was unchanged or reduced within the layers, away from the boundaries.

In cases $\mathrm{G}$ and $\mathrm{H}$, a more realistic representation of subsurface was analysed including several layers with complex geometries and considering thermal effects in Case H. Figure 21 and Figure 23 demonstrated the continuous change in the magnitudes and orientations of stresses around the wellbore in such a complex geometry. This emphasises the concern that simply using Kirsch's equations for estimating stress perturbations around wellbores can cause expensive problems in well design and operation. 
The error of Kirsch's equations in estimating far field stresses was calculated by comparing those applied to the models and the ones calculated using rearranged Kirsch's equations, as illustrated in . In this process, results from FEA were used in equation (9) to estimate stresses around wellbores. The maximum errors observed in all the considered cases are summarised in Table 5.

For comparison purposes, errors of Kirsch's equation in estimation of stresses around wellbores, i.e. step 1 of the flowchart (see ), are also presented in Table 6. This is a summary of the extensive finite element analyses conducted considering layering heterogeneity, thermal perturbations, well deviation, etc.

Using finite element simulations, it was demonstrated that the change in the stress perturbations around a wellbore could occur due to the inclination of the wellbore, the material heterogeneity due to layering, and the wellbore intersecting the frictional interfaces at faults. Changes in the orientation of stresses in inclined wellbores compared to the vertical ones were also observed and modelled using analytical solutions by Peška and Zoback (1995) and Barton et al. (1997). Changes in the magnitude and orientation of horizontal stresses due to wellbores intersecting faults were also reported in a variety of tectonic regions and rock types by Barton and Zoback (1994). They successfully explained these changes by developing an analytical method which uses an estimation of slip magnitude on a fault for calculation of the change in the stress state. FEA results demonstrated that such changes in stress orientation and magnitude may also occur in the vicinity of the interfaces of a particular layer with other layers due to the discontinuity in mechanical properties of the surrounding rock.

\section{CONCLUSIONS}

Acoustic logging as well as wellbore break-out and extended leak-off tests use stress concentration around wellbores to estimate far-field stresses employing Kirsch's equations. However, near wellbore stresses are perturbed significantly due to the presence of geologic heterogeneities and thermal effects. Additionally, inaccuracies in the acoustic measurements result in errors in the estimation of far field stresses. 
For a simple case of a homogeneous material, errors due to uncertainties in acoustic measurements were not found to be significant especially if they were complemented by borehole break-out and extended leak-off tests. However, errors around 20\% were observed in the magnitude of stresses.

Kirsch's equations commonly used as a prior in the wave-speed stress model are a simplification of how near well stresses relate to far field stresses. Comparative more realistic finite-element analysis showed that large errors in the estimated far field stresses, up to $25 \%$ in the magnitude, and up to 90 degrees in the orientation, can arise if Kirsch's equations are used. FE models considered effects such as complex geometries and layering, deviated wells, frictional interfaces, thermal effects and pore pressure. Also, it was shown that similar errors occur if Kirsch's equations are used to estimate stress perturbations around wellbores having the far field stresses.

The influence of thermal perturbations induced by drilling mud circulation on the stress which is normally not considered was also fund to be significant. Hence, near well stresses need to be corrected for the thermal effects if a realistic estimate of the far-field stress is to be obtained.

\section{ACKNOWLEDGEMENTS}

Caroline Millotte (FEI Inc., Canberra, Australia) is thanked for the generation of the more complex facies model and mesh. Their original geometries were generated with SBED, Geomodelling Technology Corp., Alberta, Canada.

\section{CONFLICT OF INTEREST}

On behalf of all authors, the corresponding author states that there is no conflict of interest.

\section{REFERENCES}

Abousleiman Y, Ekbote S (2005) Solutions for the Inclined Borehole in a Porothermoelastic Transversely Isotropic Medium Journal of Applied Mechanics 72:102-114 doi:10.1115/1.1825433

Al-Tahini A, Abousleiman Y (2008) Acoustic Measurement and Calibration of In Situ Stress Anisotropy Around a Wellbore. 2008/1/1/

Anderson EM (1951) The Dynamics of Faulting and Dyke Formation with Applications to Britain. Oliver and Boyd, Edinburgh

Barber JR (2010) Elasticity. Springer, 
Barton CA, Moos D, Peska P, Zoback MD (1997) Utilizing Wellbore Image Data To Determine The Complete Stress Tensor: Application To Permeability Anisotropy And Wellbore Stability

Barton CA, Zoback MD (1994) Stress perturbations associated with active faults penetrated by boreholes: Possible evidence for near-complete stress drop and a new technique for stress magnitude measurement Journal of Geophysical Research: Solid Earth 99:9373-9390 doi:10.1029/93JB03359

Boness NL, Zoback MD (2004) Stress-induced seismic velocity anisotropy and physical properties in the SAFOD Pilot Hole in Parkfield, CA Geophysical Research Letters 31:n/a-n/a doi:10.1029/2003GL019020

Brandas LT, Fjær E, Tokle K, Tronvoll J (2012) Relating Acoustic Wave Velocities to Formation Mechanical Properties. 2012/1/1/

Byerlee JD (1978) Friction of rock Pure \& Applied Geophysics 116

Chang C, Zoback MD, Khaksar A (2006) Empirical relations between rock strength and physical properties in sedimentary rocks Journal of Petroleum Science and Engineering 51:223-237 doi:http://dx.doi.org/10.1016/j.petrol.2006.01.003

Coulomb CA (1773) Sur une application des regles de maximums et minimums a quelques problemes de statistique relatifs a larchitesture, Acad. Roy Sci Mem Mech Min Sci 7

Ellis DV, Singer JM (2007) Well Logging for Earth Scientists. Springer Science \& Business Media,

Fjær E, Holt RM, Horsrud P, Raaen AM, Risnes R (2008) Petroleum Related Rock Mechanics. Elsevier,

Gaede O, Karpfinger F, Jocker J, Prioul R (2012) Comparison between analytical and 3D finite element solutions for borehole stresses in anisotropic elastic rock International Journal of Rock Mechanics and Mining Sciences 51:53-63 doi:https://doi.org/10.1016/j.ijrmms.2011.12.010

Gaines S, Diederichs MS, Hutchinson DJ (2012) Review of Borehole In Situ Stress Measurement Techniques For Various Ground Conditions And Numerical Stress Estimation Considerations. 2012/1/1/

Goodman HE, Connolly P (2007) Reconciling subsurface uncertainty with the appropriate well design using the Mechanical Earth Model (MEM) approach. 2007/1/1/

Grandi S, Rao RVN, Toksoz MN (2002) Geomechanical Modeling of In-Situ Stresses Around a Borehole. http://hdl.handle.net/1721.1/67848

Hoeink T, van der Zee W, Moos D (2012) Finite Element Analysis of Stresses Induced By Gravity In Layered Rock Masses With Different Elastic Moduli. 2012/1/1/

Huang S, Burns DR, Toksoez NM (2001) The effect of stresses on the sound velocity in rocks: theory of acoustoelasticity and experimental measurements. Massachusetts Institute of Technology. Earth Resources Laboratory, http://eaps.mit.edu/erl/research/report1/pdf/huang.pdf.

Jha B, Juanes R (2007) A locally conservative finite element framework for the simulation of coupled flow and reservoir geomechanics Acta Geotechnica 2:139-153 doi:10.1007/s11440-007-00330

Kirsch EG (1898) Die Theorie der Elastizität und die Bedürfnisse der Festigkeitslehre Zeitschrift des Vereines deutscher Ingenieure 42:797-807

Mavko G, Mukerji T, Dvorkin J (2003) The Rock Physics Handbook: Tools for Seismic Analysis of Porous Media. Cambridge University Press.

Padmanabhan E, Sivapriya B, Huang KH, Askury AK, Chow WS (2015) The impact of stylolites and fractures in defining critical petrophysical and geomechanical properties of some carbonate rocks Geomechanics and Geophysics for Geo-Energy and Geo-Resources 1:55-67 doi:10.1007/s40948-015-0007-x

Peng S, Zhang J (2007) Engineering Geology for Underground Rocks. Springer Berlin

Peška P, Zoback MD (1995) Compressive and tensile failure of inclined well bores and determination of in situ stress and rock strength Journal of Geophysical Research: Solid Earth 100:1279112811 doi: $10.1029 / 95 J B 00319$

Sayers CM (2005) Sensitivity of elastic-wave velocities to stress changes in sandstones The Leading Edge 24:1262-1266 doi:10.1190/1.2149646 
Sayers CM, Nagy Z, Adachi J, Singh V, Tagbor K, Hooyman P (2009) Determination of in-situ stress and rock strength using borehole acoustic data. Paper presented at the International Exposition and Annual Meeting - SEG, Houston,

Schlumberger (2005) Sonic Scanner. Schlumberger Marketing Communications,

Sinha BK (2002) Determining stress parameters of formations from multi-mode velocity.

Sinha BK et al. (2008) Estimation of formation stresses using borehole sonic data. Paper presented at the SPWLA 49th Annual Logging Symposium, May 25-28, 2008

Sirat M, Zhang X, Simon J, Vantala A, Povstyanova M (2014) Mechanical Layering: Implications for Hydraulic Fracturing in an Unconventional Tight Carbonate Reservoir in Abu Dhabi, UAE. $2014 / 2 / 25 /$

Zoback MD (2007) Reservoir Geomechanics. Cambridge University Press,

Zoback MD, Healy JH (1984) Friction, faulting, and "in situ" stresses Annales Geophysicae 2:689698

Zoback MD, Mastin L, Barton C In-situ stress measurements in deep boreholes using hydraulic fracturing, wellbore breakouts, and stonely wave polarization. In: Proceedings of the International Symposium on Rock Stress and Rock Stress Measurements, Stockholm, September, 1986 1986. International Society for Rock Mechanics, ISRM,

\section{LIST OF FIGURES}

Figure 1. Flowchart for calculation of errors due to the use of Kirsch's equations for estimation of far field stresses. The numbers show the steps of the process.

Figure 2. Selected FE models: (a) deviated wellbore in layered rocks with inclination $11^{\circ}$ (Model B);

(b) deviated wellbore in layered rocks with inclination $22^{\circ}$ (Model C); (c) geological bedding (Model D).

Materials associated with colours: Grey: Sandstone; Shale: red; Green: Limestone.

Figure 3. Probabilistic distribution of $V_{S 1}$ and $V_{S 2}$; (a) independent uncertainty; (b) dependent uncertainty.

Figure 4. Radial (left) and hoop stresses (right) around the borehole; plane-strain case. $\sigma_{\mathrm{H}}=\sigma_{\mathrm{X}-\mathrm{X}}=$ 63.75MPa, $\sigma_{\mathrm{h}}=\sigma_{\mathrm{Y}-\mathrm{Y}}=56.25 \mathrm{MPa}$. Note: $\mathrm{S} 11$ and $\mathrm{S} 22$ refer to the radial and hoop stresses in a cylindrical coordinate system with its origin set to the centre of the wellbore. Avg $75 \%$ indicates that nodal results are the average of the extrapolated values from the elements connected to a node, if the difference among the values is less than $25 \%$. Otherwise, values from different elements are not averaged on nodes and are shown as discontinuity in contours.

Figure 5. Hoop stresses around wellbore for the 2D plane-strain case (angle w.r.t. $\sigma_{\mathrm{H}}$ ). FEM vs.

Kirsch's equations 
Figure 6. Case A. Hoop stress distribution around wellbore. $\sigma_{\mathrm{V}}=\sigma_{\mathrm{Y}-\mathrm{Y}}=75 \mathrm{MPa}, \sigma_{\mathrm{H}}=\sigma_{\mathrm{X}-\mathrm{X}}=63.75 \mathrm{MPa}$, $\sigma_{\mathrm{h}}=\sigma_{\mathrm{Z}-\mathrm{Z}}=56.25 \mathrm{MPa}$.

Figure 7. Case A. Hoop stress magnitude and orientation around wellbore. FEM vs. Kirsch's equation. Maximum hoop stress orientation is given by the right hand side vertical axis. Stress magnitudes and orientations predicted by Kirsch's equations are shown as straight solid lines.

Figure 8. Case B. Hoop stress distribution around wellbore. $\sigma_{\mathrm{V}}=\sigma_{\mathrm{Y}-\mathrm{Y}}=75 \mathrm{MPa}, \sigma_{\mathrm{H}}=\sigma_{\mathrm{X}-\mathrm{X}}=63.75 \mathrm{MPa}$, $\sigma_{\mathrm{h}}=\sigma_{\mathrm{Z}-\mathrm{Z}}=56.25 \mathrm{MPa}$.

Figure 9. Case B. Hoop stress magnitude and orientation around wellbore. FEM vs. Kirsch's equation Figure 10. Case C. Hoop stress distribution around wellbore. Note: Deformations are magnified. $\sigma_{\mathrm{V}}=$ $\sigma_{\mathrm{Y}-\mathrm{Y}}=75 \mathrm{MPa}, \sigma_{\mathrm{H}}=\sigma_{\mathrm{X}-\mathrm{X}}=63.75 \mathrm{MPa}, \sigma_{\mathrm{h}}=\sigma_{\mathrm{Z}-\mathrm{Z}}=56.25 \mathrm{MPa}$.

Figure 11. Case C. Hoop stress magnitude and orientation around wellbore. FEM vs Kirsch's equation Figure 12. Case D. Temperature change around wellbore. Note: Deformations are magnified. NT11: bedrock temperature.

Figure 13. Case D. Hoop stress magnitude and orientation around wellbore. FEM vs Kirsch's equation

Figure 14. Case C vs. Case D. Comparison of Max hoop stress with and without thermal effects

Figure 15. Case E. Hoop stress distribution around wellbore. Note: Deformations are magnified. $\sigma_{\mathrm{V}}=$ $\sigma_{\mathrm{Y}-\mathrm{Y}}=75 \mathrm{MPa}, \sigma_{\mathrm{H}}=\sigma_{\mathrm{X}-\mathrm{X}}=63.75 \mathrm{MPa}, \sigma_{\mathrm{h}}=\sigma_{\mathrm{Z}-\mathrm{Z}}=56.25 \mathrm{MPa}$.

Figure 16. Case E. Hoop stress magnitude and orientation around wellbore. FEM vs Kirsch's equation

Figure 17. Case F. Effective hoop stress distribution around wellbore. Note: Deformations are magnified. $\sigma_{\mathrm{V}}=\sigma_{\mathrm{Y}-\mathrm{Y}}=75 \mathrm{MPa}, \sigma_{\mathrm{H}}=\sigma_{\mathrm{X}-\mathrm{X}}=63.75 \mathrm{MPa}, \sigma_{\mathrm{h}}=\sigma_{\mathrm{Z}-\mathrm{Z}}=56.25 \mathrm{MPa}$

Figure 18. Case F. Effective hoop stress magnitude and orientation around the wellbore

Figure 19. Case F. Influence of Pore Pressure (PP) on total stresses around the wellbore 
Figure 20. Case G. Hoop stress distribution around wellbore. $\sigma_{\mathrm{V}}=\sigma_{\mathrm{Y}-\mathrm{Y}}=75 \mathrm{MPa}, \sigma_{\mathrm{H}}=\sigma_{\mathrm{X}-\mathrm{X}}=63.75 \mathrm{MPa}$, $\sigma_{\mathrm{h}}=\sigma_{\mathrm{Z}-\mathrm{Z}}=56.25 \mathrm{MPa}$.

Figure 21. Case G. Hoop stress distribution around the wellbore. Note: Stress orientation variation is shown on the right on the wellbore surface.

Figure 22. Case H. Temperature (Left) and stress distribution in the direction of SHmax (Right). $\sigma_{V}=$ $\sigma_{\mathrm{Y}-\mathrm{Y}}=75 \mathrm{MPa}, \sigma_{\mathrm{H}}=\sigma_{\mathrm{X}-\mathrm{X}}=63.75 \mathrm{MPa}, \sigma_{\mathrm{h}}=\sigma_{\mathrm{Z}-\mathrm{Z}}=56.25 \mathrm{MPa}$.

Figure 23. Case H. Hoop stress magnitude and orientation around the wellbore

Figure 24. Case G vs. Case H. Comparison of Max hoop stress with and without thermal effects

\section{LIST OF TABLES}

Table 1. Input values used for error estimations in using sonic logging

Table 2. Description of simulation cases

Table 3. Rock properties used in cases A - F (Mavko et al. 2003)

Table 4. Input variables for Monte-Carlo simulation

Table 5. Errors in calculation of far field stresses using Kirsch's equations. Comparison of values calculated using equation (9) and the applied far-field stresses of $\sigma_{H}=63.75 \mathrm{MPa}$ and $\sigma_{h}=56.25 \mathrm{MPa}$

Table 6. Errors of Kirsch's equations in estimation of stresses around wellbores $\left(\sigma_{H}=105 \mathrm{MPa}\right.$ and $\sigma_{H}$ $=75 \mathrm{MPa}$ based on Kirsch equations)

Table 1. Input values used for error estimations in using sonic logging

\begin{tabular}{|l|l|l|}
\hline Variables & Values & Sources \\
\hline$\sigma_{V}$ & $20.7 \mathrm{MPa}$ & Sinha et al. (2008) \\
\hline
\end{tabular}




\begin{tabular}{|l|l|l|}
\hline$p_{p}$ & $7.6 \mathrm{MPa}$ & Sinha et al. (2008) \\
\hline$V_{C}$ & $3800 \mathrm{~m} / \mathrm{s}$ & Ellis \& Singer (2007) \\
\hline$V_{S 1}$ & $1553 \mathrm{~m} / \mathrm{s}$ & Sinha et al. (2008) \\
\hline$V_{S 2}$ & $1539 \mathrm{~m} / \mathrm{s}$ & Sinha et al. (2008) \\
\hline$V_{\text {stoneley }}$ & $1360 \mathrm{~m} / \mathrm{s}$ & Sinha et al. (2008) \\
\hline$\sigma_{h}$ (Case 1. In situ measurement) $)$ & $11.5 \mathrm{MPa}$ & Sinha et al. (2008) \\
\hline
\end{tabular}

Table 2. Description of simulation cases

\begin{tabular}{|l|l|}
\hline Simulation Case & Description \\
\hline Case A & Vertical well in a layered rock using Model A. \\
\hline Case B & Deviated well in layered rock - inclination 11 degrees using Model B. \\
\hline Case C & Deviated well in layered rock - inclination 22 degrees using Model C. \\
\hline Case D & $\begin{array}{l}\text { Deviated wellbore in layered rock including thermal perturbations - inclination 22 degree } \\
\text { using Model C. }\end{array}$ \\
\hline Case E & $\begin{array}{l}\text { Deviated wellbore in layered rock with frictional interfaces - inclination 22 degrees using } \\
\text { Model C. }\end{array}$ \\
\hline Case F & $\begin{array}{l}\text { Deviated wellbore in layered rock with frictional interfaces and pore pressure simulation - } \\
\text { inclination 22 degree using Model C. }\end{array}$ \\
\hline Case G & $\begin{array}{l}\text { Cross-bedded geological model including frictional interfaces using Model D. } \\
\text { Case H }\end{array}$ \\
\hline
\end{tabular}

Table 3. Rock properties used in cases A - F (Mavko et al. 2003)

\begin{tabular}{|l|l|l|l|l|l|l|}
\hline Rock type & Elastic & Poisson's & Thermal & Thermal & Hydraulic & Void \\
& Modulus & ratio & expansion & Conductivity & Conductivity & ratio \\
\hline
\end{tabular}




\begin{tabular}{|l|c|c|c|c|c|c|}
\hline & $(\mathrm{GPa})$ & & $\begin{array}{l}\text { coefficient }\left(\mathrm{K}^{-1}\right) \\
(\text { Wases E, I })\end{array}$ & $\begin{array}{l}\text { W/(mK) } \\
(\text { Cases E, I })\end{array}$ & & F) \\
\hline Quartz & 20 & 0.25 & $1.16 \times 10^{-5}$ & 1.7 & $1 \times 10^{-6}$ & 0.19 \\
Sandstone & & & & & & \\
\hline Shale & 10 & 0.4 & $9 \times 10^{-6}$ & 1.0 & $1 \times 10^{-10}$ & 0.053 \\
\hline Limestone & 30 & 0.2 & $8 \times 10^{-6}$ & 1.3 & $1 \times 10^{-8}$ & 0.18 \\
\hline
\end{tabular}

Table 4. Input variables for Monte-Carlo simulation

\begin{tabular}{|c|c|c|c|c|c|}
\hline Value & $\begin{array}{l}\text { Mean } \\
(\mathrm{MPa})\end{array}$ & $\begin{array}{l}\text { Standard } \\
\text { Dev. }(\mathrm{MPa})\end{array}$ & $\begin{array}{l}\text { Precision for } 86.6 \% \\
\text { confidence (MPa / } \\
\text { Percentage) }\end{array}$ & $\begin{array}{l}\text { Precision for } 95.4 \% \\
\text { confidence (MPa / } \\
\text { Percentage) }\end{array}$ & $\begin{array}{l}\text { Precision for } 99.8 \% \\
\text { confidence (MPa } \\
\text { Percentage })\end{array}$ \\
\hline$\overline{\sigma_{h}}$ & 14.66 & 0.34 & $\pm 0.51(3.4 \%)$ & $\pm 0.67(4.6 \%)$ & $\pm 1.01(6.9 \%)$ \\
\hline$\sigma_{H}($ Case 1$)$ & 15.71 & 0.31 & $\pm 0.47(3.0 \%)$ & $\pm 0.62(4.0 \%)$ & $\pm 0.94(6.0 \%)$ \\
\hline$\sigma_{H}($ Case 2) & 15.71 & 0.002 & 0.00 & 0.00 & 0.00 \\
\hline
\end{tabular}

Table 5. Errors in calculation of far field stresses using Kirsch's equations. Comparison of values calculated using equation (9) and the applied far-field stresses of $\sigma_{H}=63.75 \mathrm{MPa}$ and $\sigma_{h}=56.25 \mathrm{MPa}$

\begin{tabular}{|l|l|l|l|l|l|}
\hline Simulation & Models & $\sigma_{H}$ from & Max $\sigma_{H}$ Error & $\sigma_{h}$ from & Max $\sigma_{h}$ Error \\
\hline
\end{tabular}




\begin{tabular}{|c|c|c|c|c|c|c|c|}
\hline Case & & $\begin{array}{l}\text { eq. (9) } \\
\text { (MPa) }\end{array}$ & $(\mathrm{MPa})$ & $(\%)$ & $\begin{array}{l}\text { eq. (9) } \\
\text { (MPa) }\end{array}$ & $(\mathrm{MPa})$ & $(\%)$ \\
\hline A & Vertical well in a layered rock & 72.6 & 8.8 & 13.9 & 56.7 & 0.5 & 0.8 \\
\hline B & $\begin{array}{l}\text { Deviated well in layered rock - } \\
\text { inclination } 11 \text { degrees }\end{array}$ & 74.3 & 10.6 & 16.6 & 57.3 & 1.0 & 1.8 \\
\hline C & $\begin{array}{l}\text { Deviated well in layered rock - } \\
\text { inclination } 22 \text { degrees }\end{array}$ & 70.5 & 6.8 & 10.6 & 58.8 & 2.6 & 4.6 \\
\hline D & $\begin{array}{l}\text { Deviated wellbore in layered rock } \\
\text { including thermal perturbations - } \\
\text { inclination } 22 \text { degree }\end{array}$ & 68.9 & 5.1 & 8.0 & 55.4 & 0.8 & 1.5 \\
\hline E & $\begin{array}{l}\text { Deviated well in layered rock with } \\
\text { frictional interfaces - inclination } \\
22 \text { degrees }\end{array}$ & 70.6 & 6.8 & 10.7 & 58.7 & 2.4 & 4.3 \\
\hline $\mathrm{F}$ & $\begin{array}{l}\text { Deviated wellbore in layered rock } \\
\text { with frictional interfaces and pore } \\
\text { pressure simulation - inclination } \\
22 \text { degree }\end{array}$ & 73.0 & 9.3 & 14.5 & 59.0 & 2.8 & 5.0 \\
\hline G & $\begin{array}{l}\text { Cross-bedded geological model } \\
\text { including frictional interfaces }\end{array}$ & 75.8 & 12.1 & 18.9 & 58.6 & 2.4 & 4.2 \\
\hline $\mathrm{H}$ & $\begin{array}{l}\text { The cross-bedded geological } \\
\text { model with frictional interfaces } \\
\text { with the effects of thermal } \\
\text { perturbations }\end{array}$ & 73.8 & 10.1 & 15.8 & 55.8 & 0.4 & 0.7 \\
\hline
\end{tabular}

Table 6. Errors of Kirsch's equations in estimation of stresses around wellbores $\left(\sigma_{H}=105 \mathrm{MPa}\right.$ and $\sigma_{H}$ =75 MPa based on Kirsch equations) 


\begin{tabular}{|l|l|c|c|c|c|c|}
\hline \multirow{2}{*}{ Simulation Case } & \multirow{2}{*}{$\begin{array}{l}\text { Max } \sigma_{\theta \max } \text { based } \\
\text { on FEA (MPa) }\end{array}$} & \multicolumn{2}{|c|}{ Max $\sigma_{\theta \max }$ Error } & \multicolumn{2}{c|}{ Max $\sigma_{\theta \min }$ based } & \multicolumn{2}{c|}{ Max $\sigma_{\theta \min }$ Error } \\
\cline { 7 - 8 } & & $(\mathrm{MPa})$ & $(\%)$ & on FEA (MPa) & $(\mathrm{MPa})$ & $(\%)$ \\
\hline $\mathrm{A}$ & 131.1 & 26.1 & 19.9 & 67.5 & 7.5 & 11.1 \\
\hline $\mathrm{B}$ & 135.7 & 30.7 & 22.6 & 67.5 & 7.5 & 11.1 \\
\hline $\mathrm{C}$ & 122.7 & 17.7 & 14.4 & 76.0 & 1.0 & 1.3 \\
\hline $\mathrm{D}$ & 121.2 & 16.2 & 13.4 & 67.4 & 7.6 & 11.3 \\
\hline $\mathrm{E}$ & 123.0 & 18.0 & 14.6 & 75.4 & 0.4 & 0.5 \\
\hline F & 130.0 & 25.0 & 19.2 & 74.1 & 0.9 & 1.2 \\
\hline G & 138.8 & 33.8 & 24.4 & 70.0 & 5.0 & 7.1 \\
\hline H & 135.6 & 30.6 & 22.6 & 63.7 & 11.3 & 17.7 \\
\hline
\end{tabular}

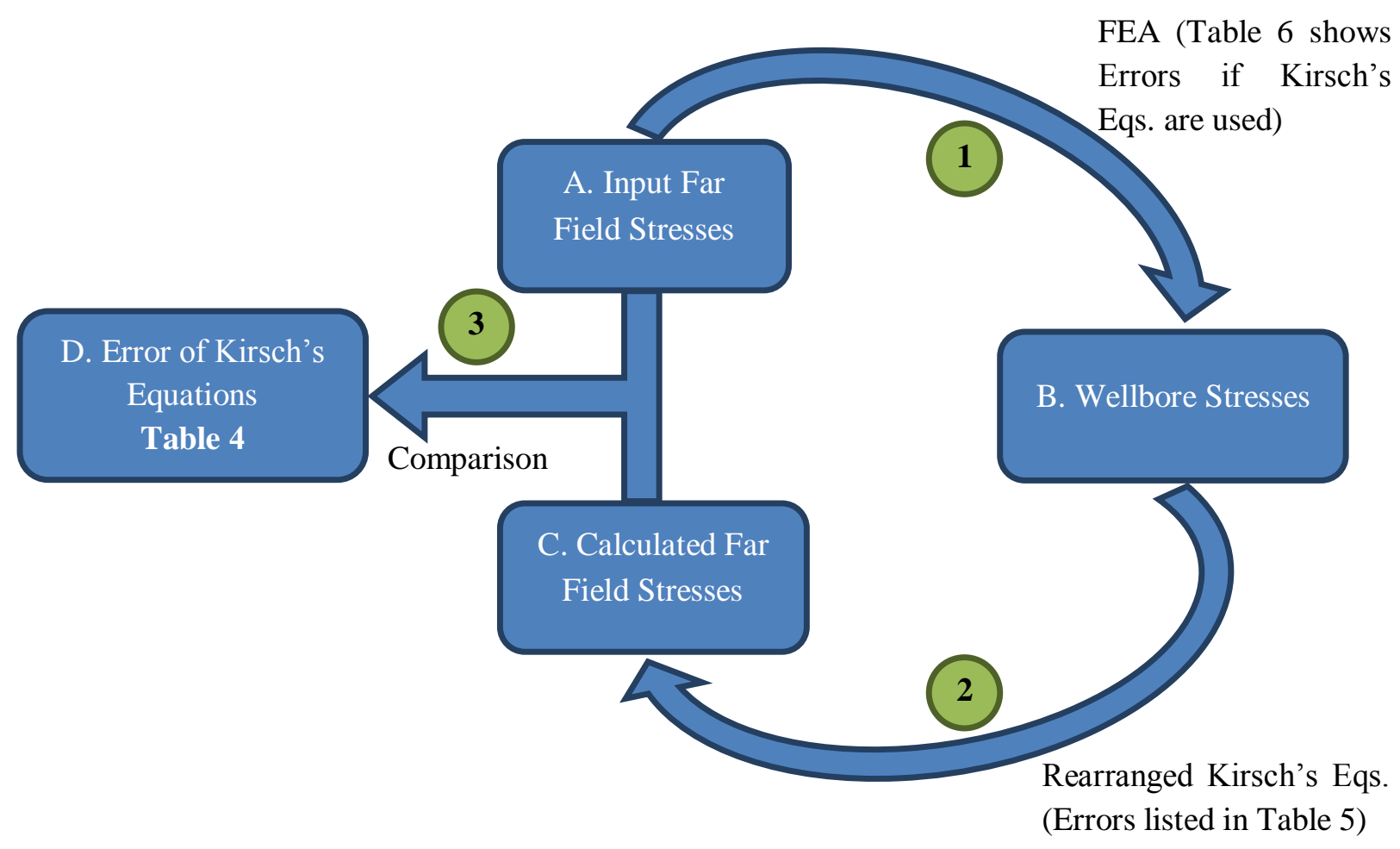



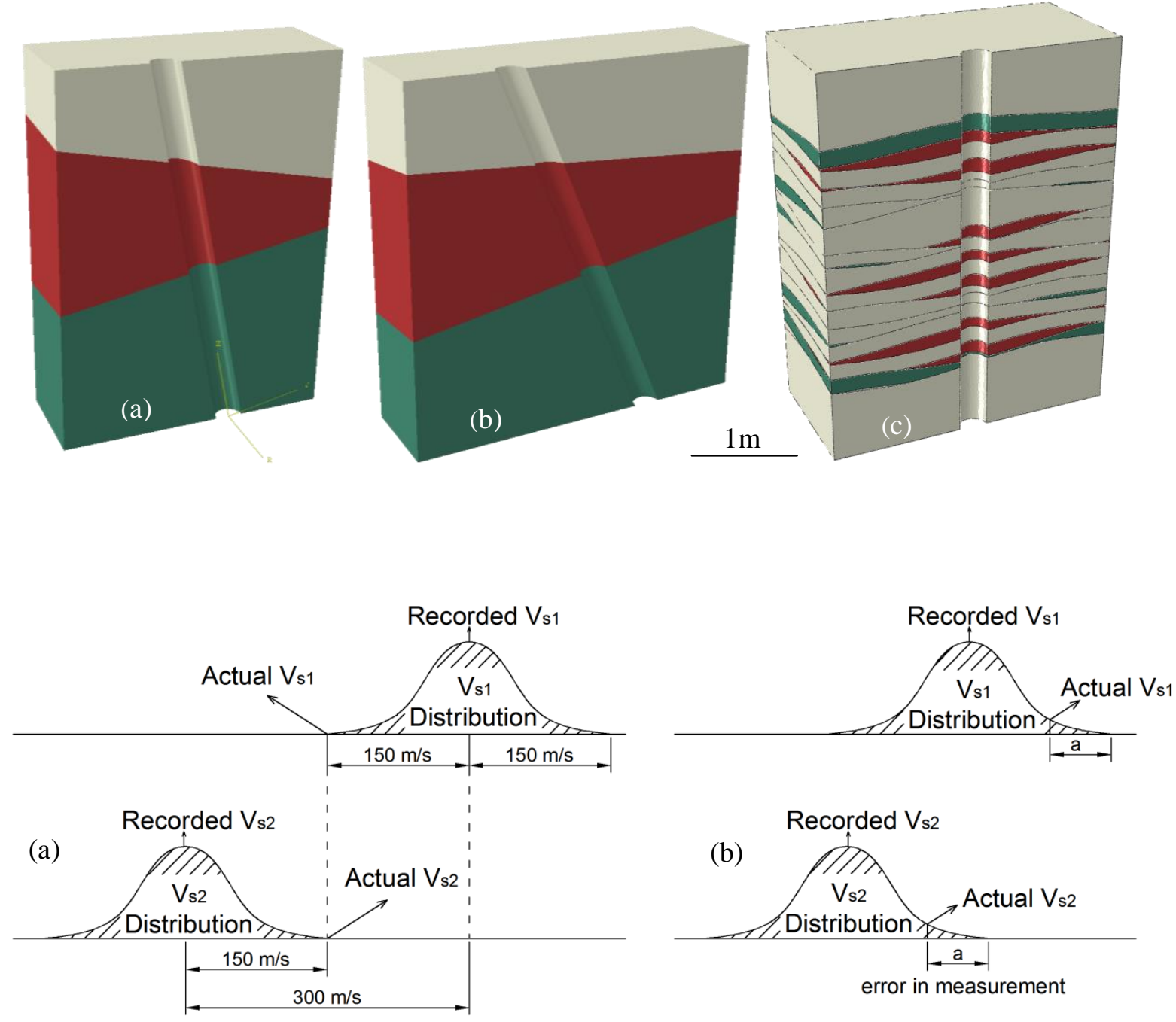

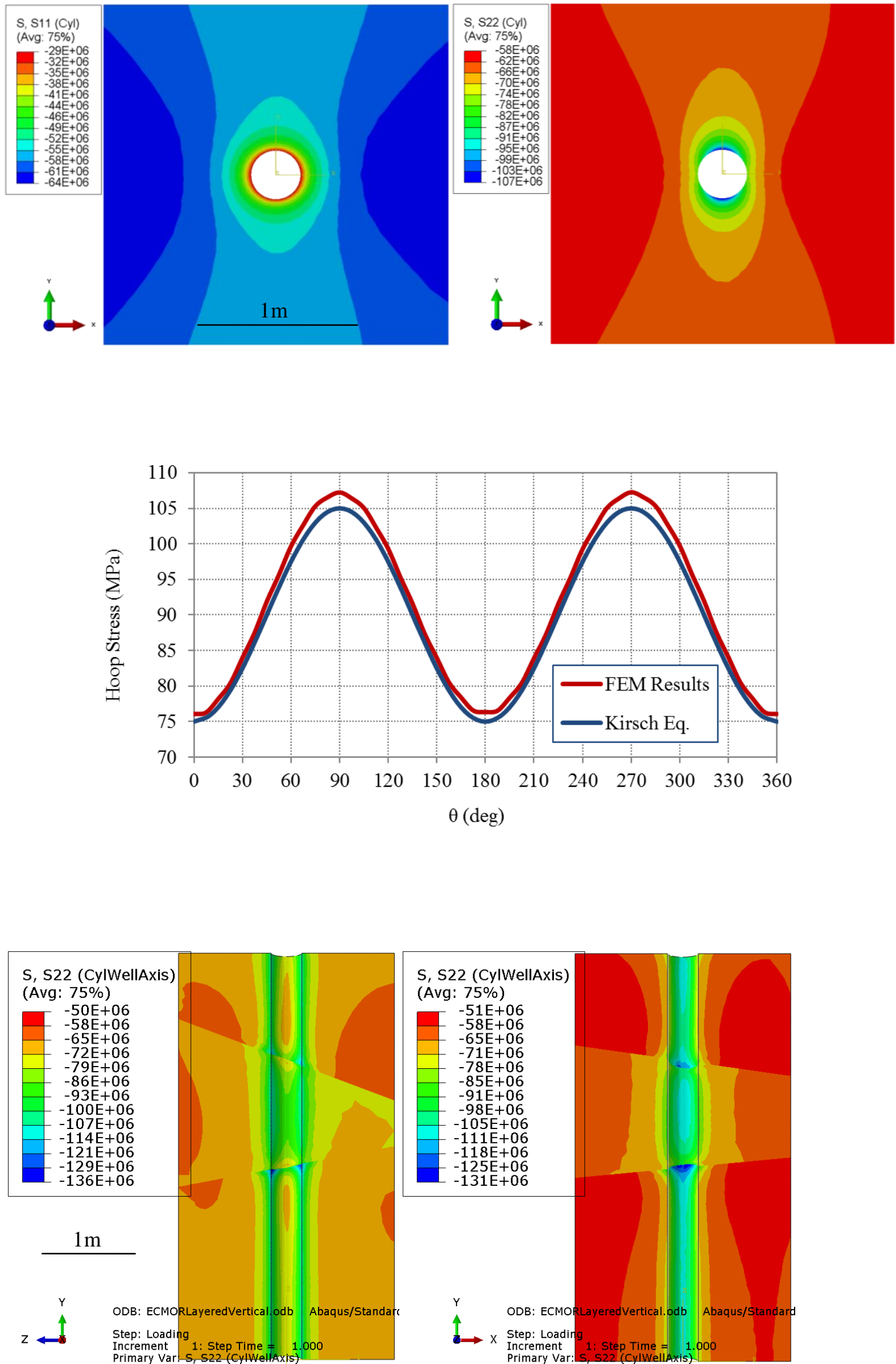

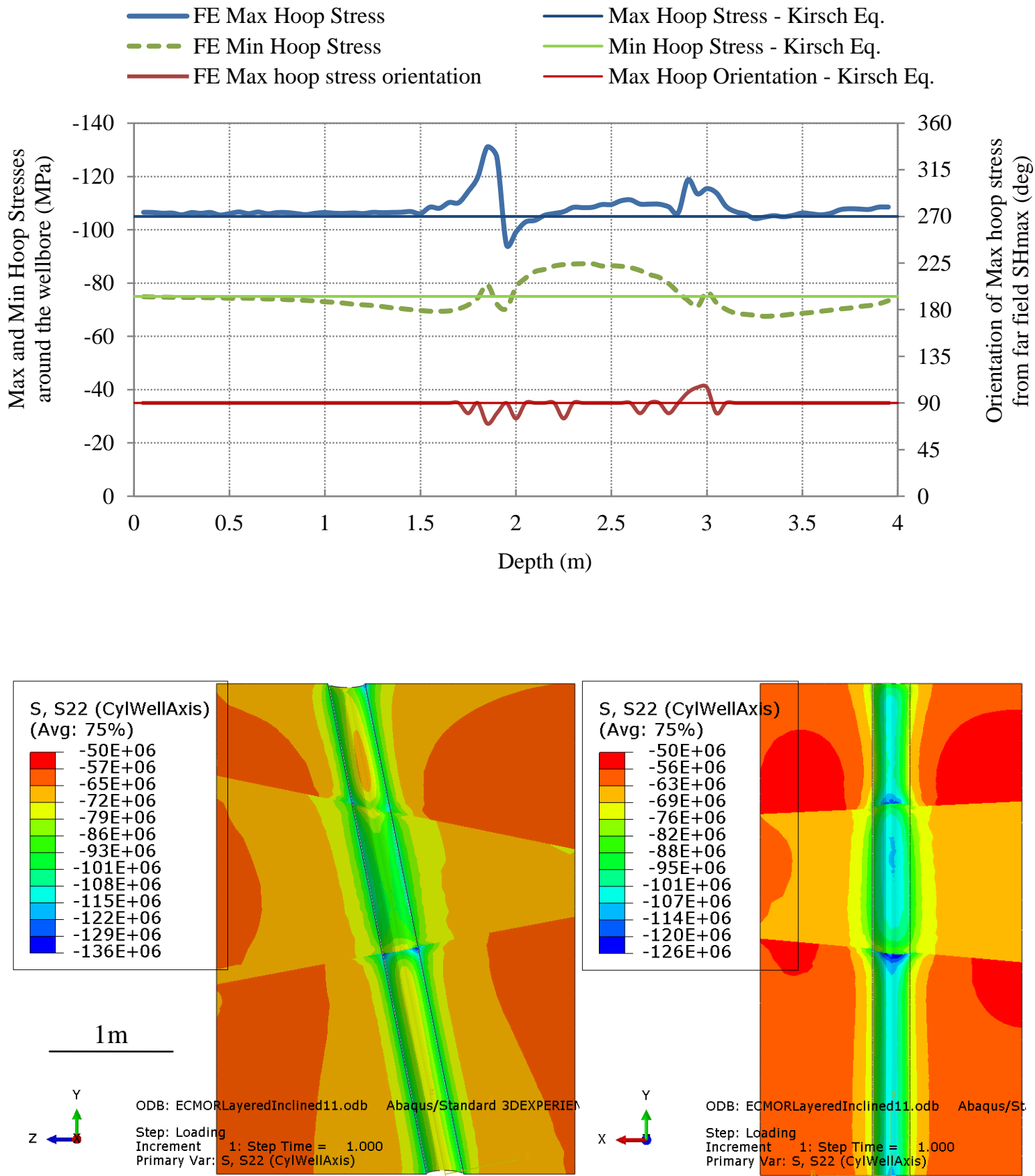

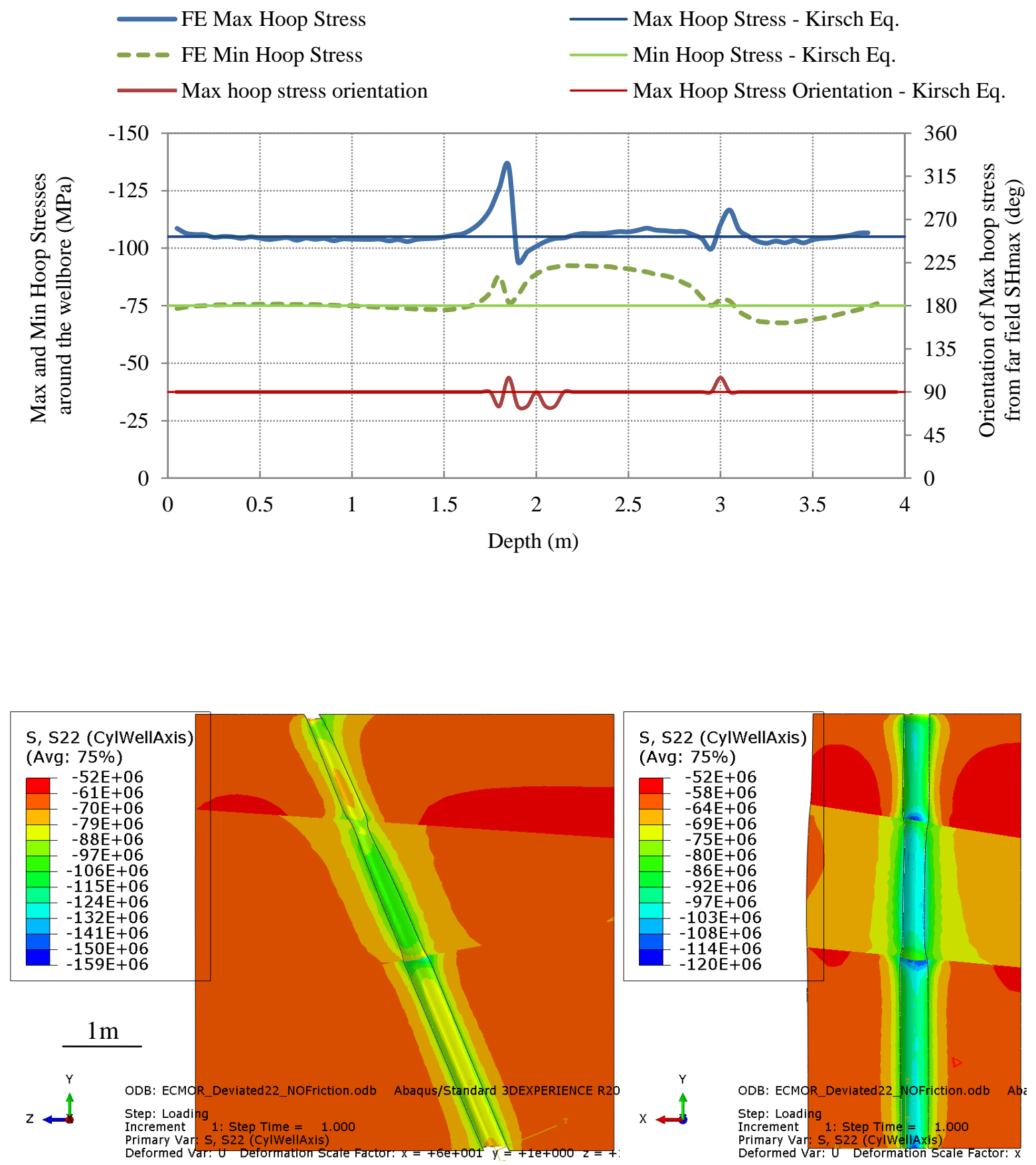

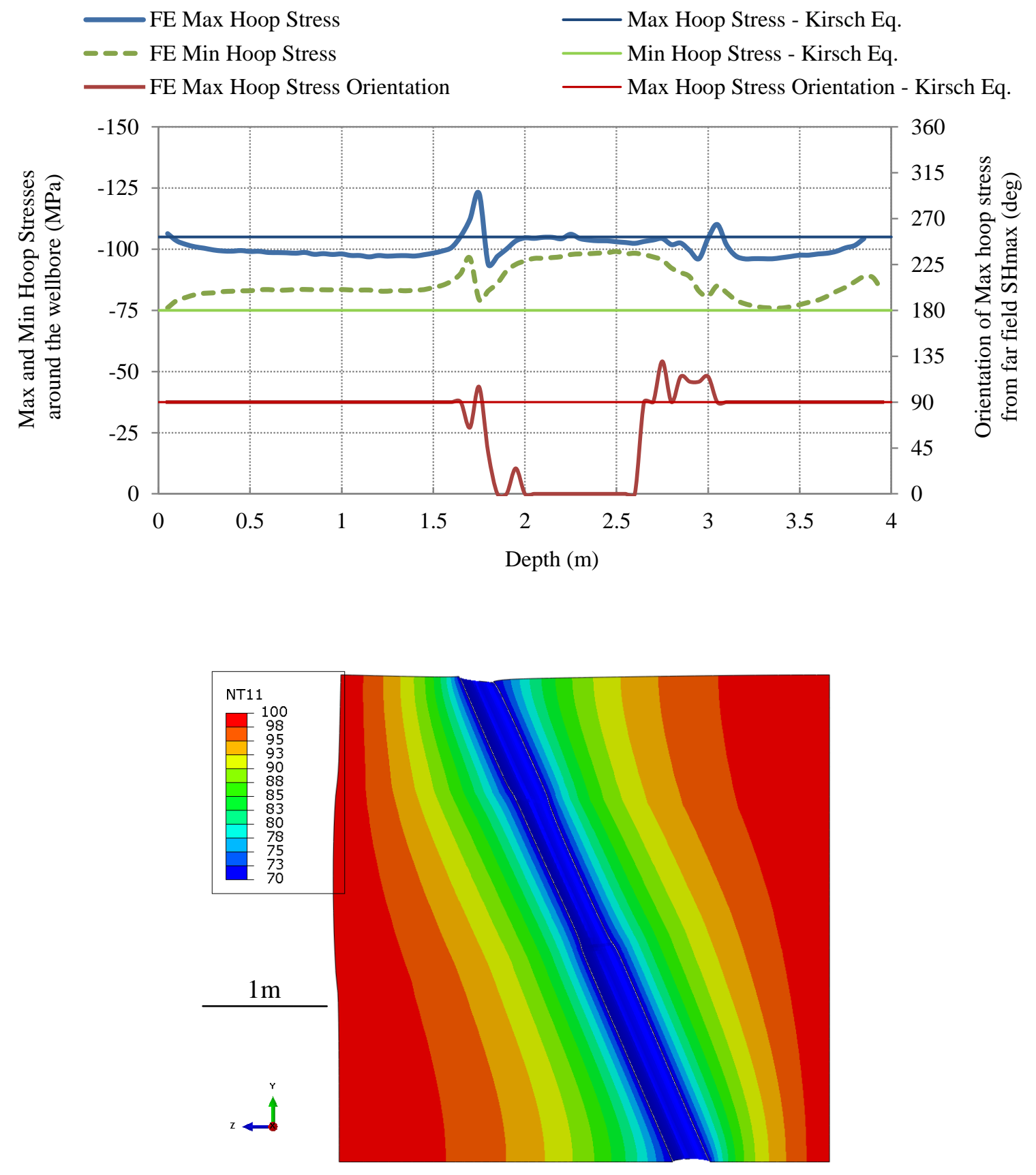

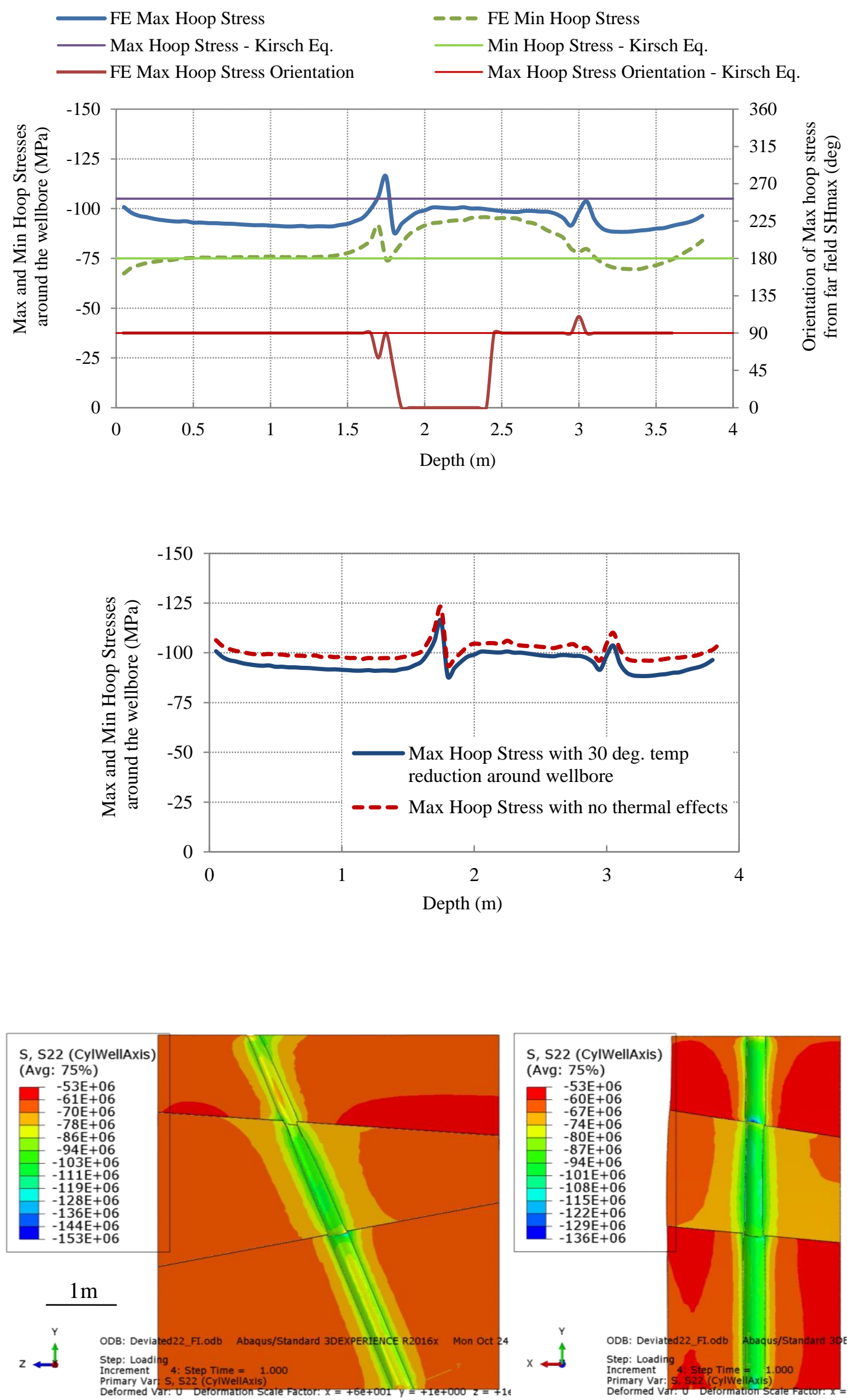

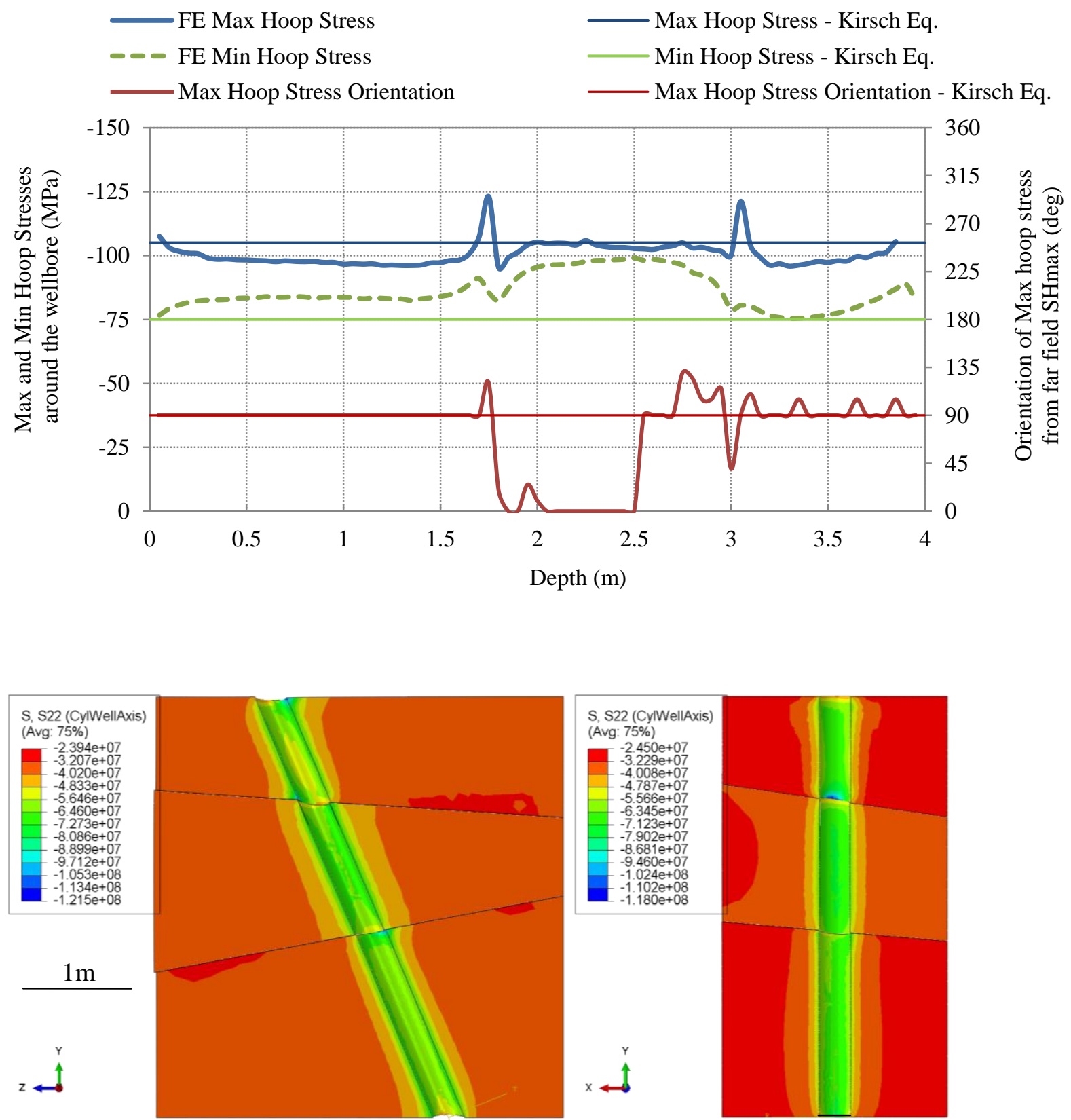

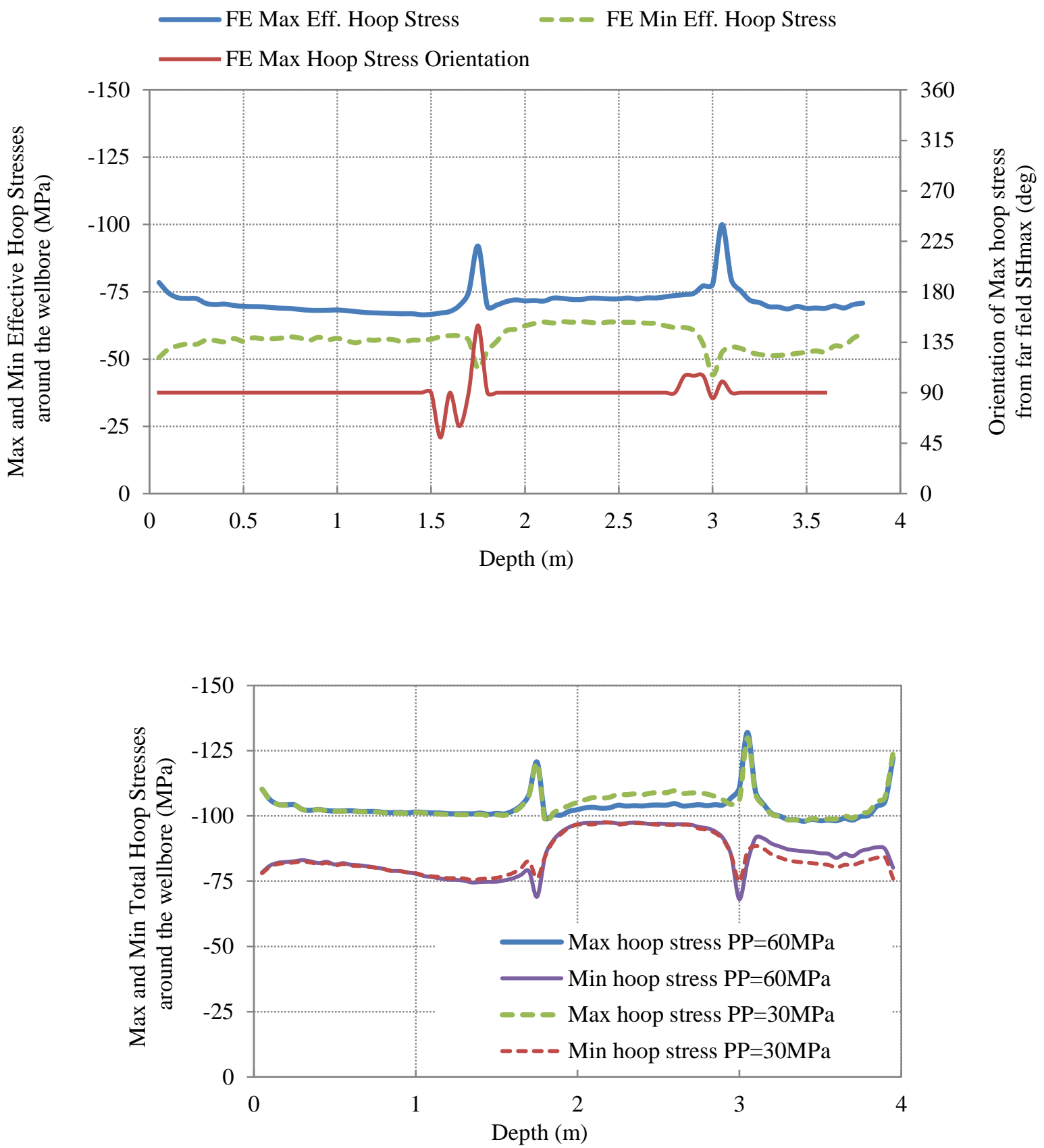


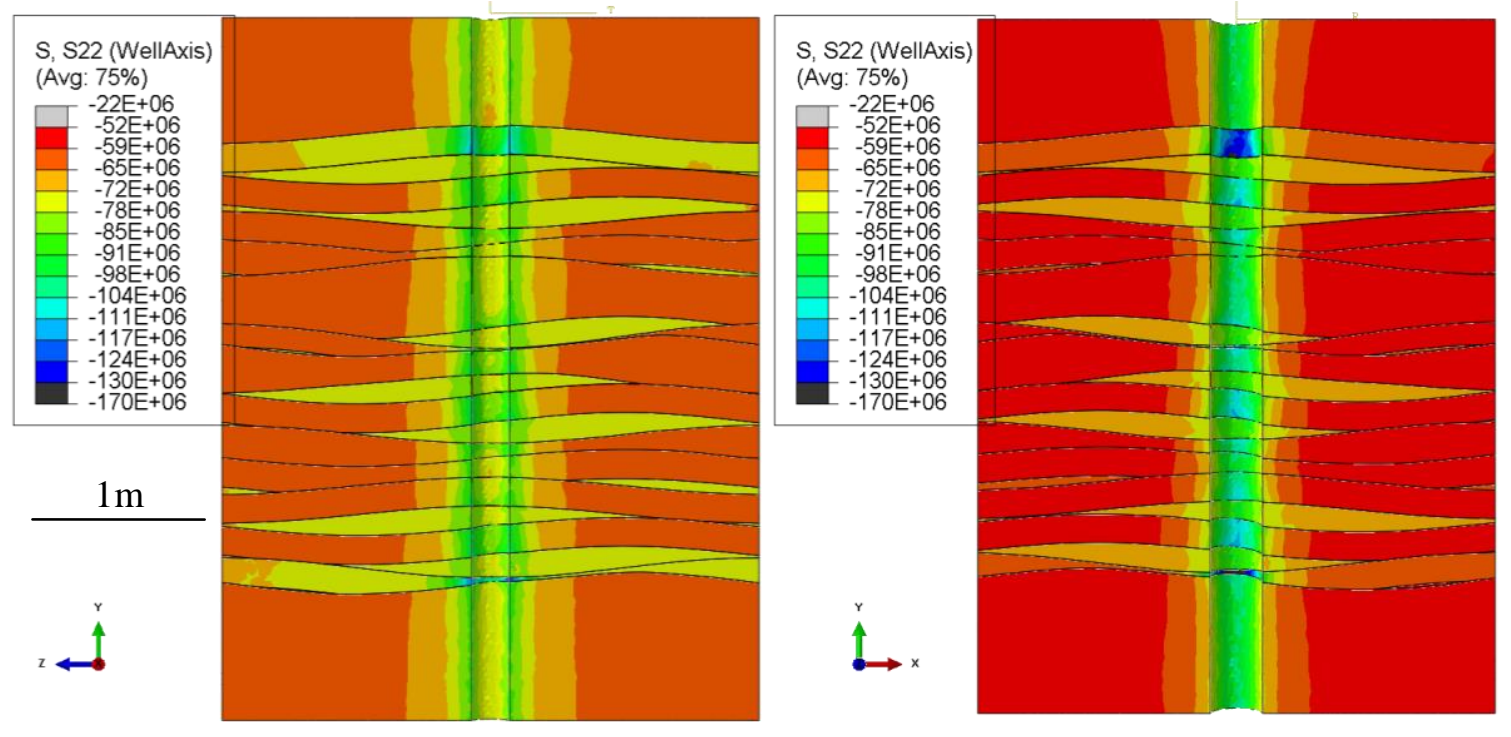

FE Max Hoop Stress

- FE Min Hoop Stress

— Max Hoop Stress - Kirsch Eq. Min Hoop Stress - Kirsch Eq.

FE Max Hoop Stress Orientation Max Hoop Stress Orientation - Kirsch Eq.

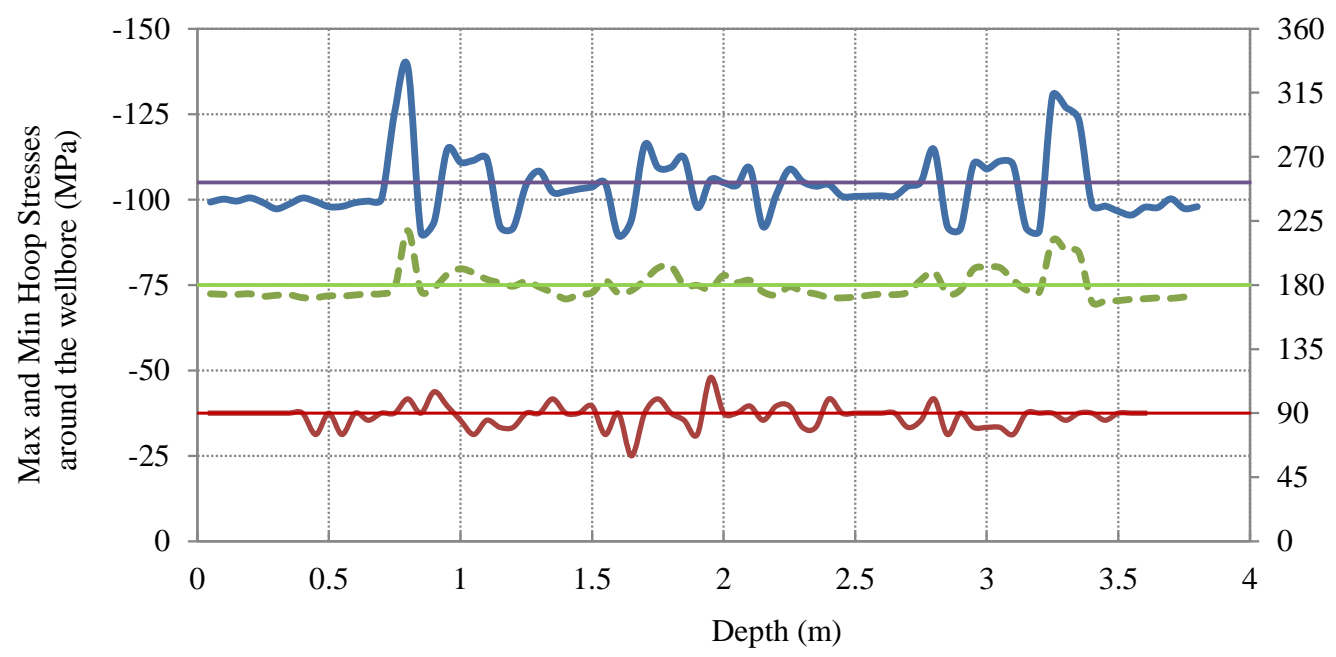

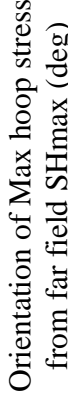

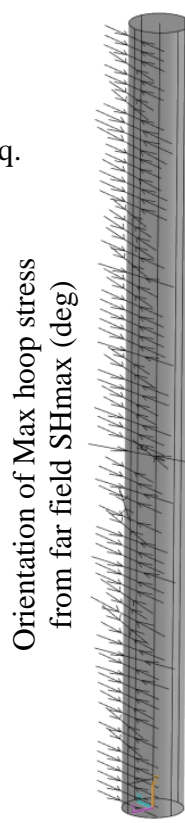



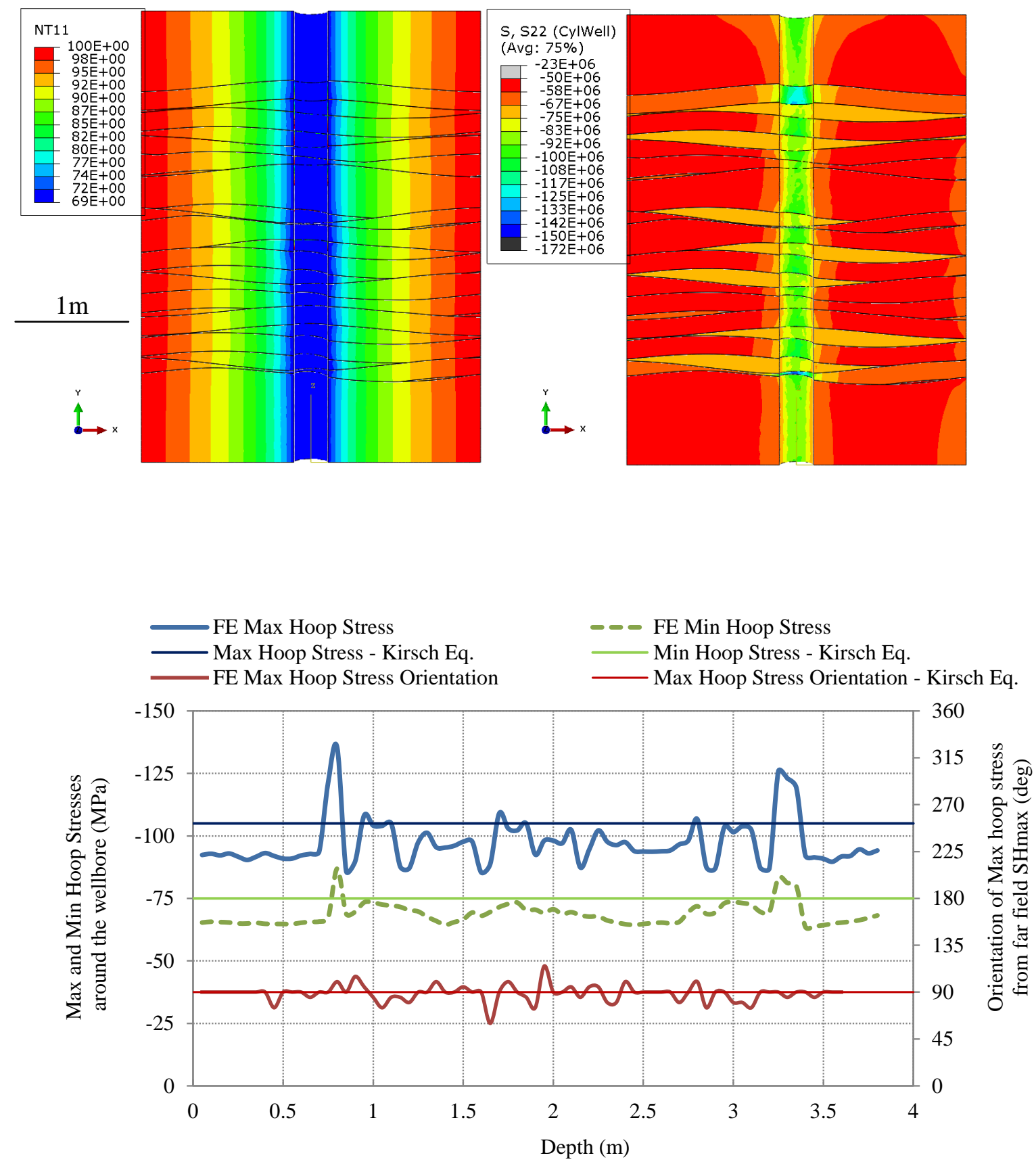


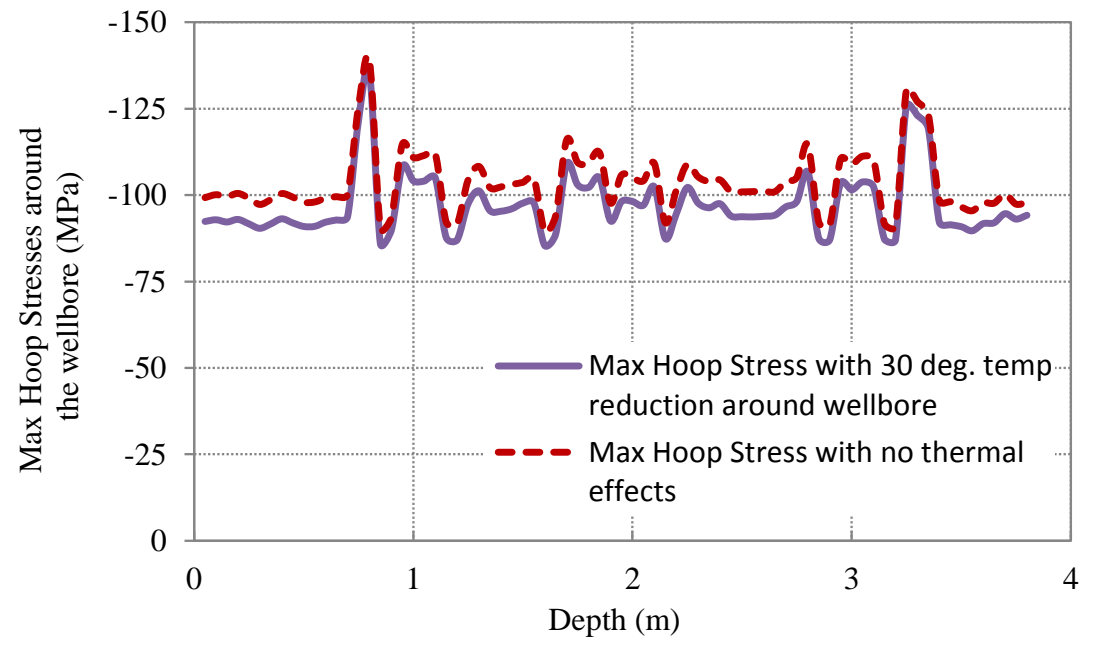




\section{University Library}

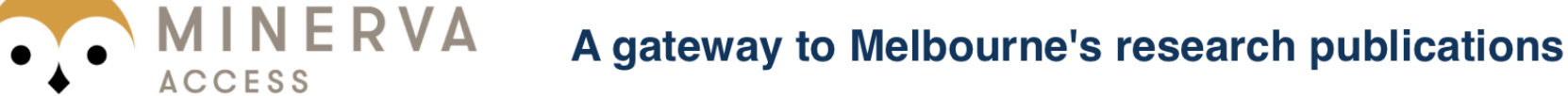

Minerva Access is the Institutional Repository of The University of Melbourne

Author/s:

Agheshlui, H;Matthai, S

Title:

Uncertainties in the estimation of in situ stresses: effects of heterogeneity and thermal perturbation

Date:

2017-12-01

Citation:

Agheshlui, H. \& Matthai, S. (2017). Uncertainties in the estimation of in situ stresses:

effects of heterogeneity and thermal perturbation. GEOMECHANICS AND GEOPHYSICS FOR GEO-ENERGY AND GEO-RESOURCES, 3 (4), pp.415-438. https://doi.org/10.1007/ s40948-017-0069-Z.

Persistent Link:

http://hdl.handle.net/11343/282565 